\title{
Creditor Protection, Judicial Enforcement and Credit Access
}

$20^{\text {th }}$ of June 2016

\begin{abstract}
We investigate the impact of the legal system on whether or not firms obtain the credit they apply for. Data comprise unique information provided directly by 48,590 firms from 11 European countries. We look at the strength of creditor protection, the strength of property rights, the time taken to resolve a dispute, the dispute resolution process's costs and the number of procedures the plaintiff faces using data provided by the World Bank and the Heritage Foundation. The results suggest that the more efficient the judicial enforcement system is, and the higher the creditor protection is, the lower the probability that the firms are partially or totally denied credit. Our results are robust to selection bias (Heckman selection) as well as different controls and different estimation techniques. We find that these variables have considerable economic impact: the probability of obtaining credit is up to $40 \%$ higher in countries with more robust legal systems.
\end{abstract}

JEL: G21

Keywords: Credit Access, Judicial System, Property Rights, Creditor Protection

\section{Introduction}

The certainty of the law and the opportunity to enforce legal rights in court can affect banks' lending decisions and therefore the firms' access to credit. Banks act as delegated monitors (Diamond 1984) and play a key role in supporting the development of the economy 
by investing people's savings in reliable firms and projects. The quality of the laws and institutions that support banks in dealing with delinquent customers is important in order to ensure that banks are able to recover the loan if a borrower defaults. In countries with strong creditor protection and rigorous law enforcement, banks will find it easier to control borrower risk and recover the loan in the event of default. As a consequence, banks will be more willing to lend ex ante(La Porta et al. 1997), reducing the firms' risk of being credit constrained. At the same time, banks will be exposed to a greater legal risk and have a lower probability to force repayment in countries with little creditor protection and feeble law enforcement (Esty and Megginson 2003). Hence, they will be reluctant to grant credit, thereby constraining the firms' credit access.

Our research builds on previous works that examine the role of a country's legal system on the firms' debt financing. Empirical evidence suggests that the level of creditor and property rights protection and the rigorousness of law enforcement affect debt ownership concentration (e.g. Esty and Megginson 2003) and the terms of the credit, such as size, maturity and interest rate of the loan agreement (Bae and Goyal 2009; Laeven and Majnoni 2005; Qian and Strahan 2007). The impact of the legal system on credit access using indirect measures of credit access, such as the proportion of overdrawn credit lines, the share of a firm's bank debt on total debt, the total supply of loans or the collateral spread, is investigated by Jappelli, Pagano, and Bianco (2005); Haselmann, Pistor, and Vig (2010); and Liberti and Mian (2010). Jappelli, Pagano, and Bianco (2005) find that longer trials increase the probability that firms have overdraft loans. The outcomes of Haselmann, Pistor, and Vig (2010) show that the overall supply of credit in developing countries increases subsequent to changes in collateral laws and bankruptcy laws. In line with these findings, Liberti and Mian (2010) suggest that in countries with stronger creditor rights and better information sharing mechanisms collateral spreads are smaller. 
Our paper is close in spirit to the work of Beck, Demirgüc-Kunt, and Levin (2004), who use direct measures of credit access, that is, data on finance obstacles perceived by firms, to examine the relationship with a country's legal system. The authors investigate the impact of the adaptability of a country's legal system and the political independence of the judiciary on firms' financing obstacles. They find that whereas cross-country variations in the legal system's adaptability help to explain differences in the financing obstacles that firms have to face, cross-country variations in the judiciary's independence do not contribute to explaining those differences. Thus, they examine specific traits of a country's legal system, but do not provide a holistic picture of the relationship between the legal system and the firms' ability to obtain credit. Further, the authors do not distinguish between firms that are financially constrained because they have problems with obtaining loans in the first place and firms that are financially constrained because they obtained only part of the loan they applied for. Our study aims to narrow this gap by: (1) examining the impact of the strength of the legal rules (i.e. creditor rights and property protection) and the rigorousness of the judicial enforcement (i.e. time required to resolve the dispute, costs and number of procedures) because the quality of legal rules and judicial enforcement can also vary independently (Pistor, Raiser, and Gelfer 2000) and can therefore affect credit access differently and (2) evaluating both firms that did not obtain any credit at all and firms that obtained credit, but not enough to satisfy their financial needs.

We rely on the Survey on the Access to Finance of Enterprises (SAFE) dataset from the European Central Bank, which collects information about access to credit and the use of different sources of finance as well as liquidity and finance constraints directly from firms. We integrate it with information on the legal systems in Europe using data from the World Bank and the Heritage Foundation. The resulting dataset contains 48,590 complete observations collected between 2009 and 2012, of which 12,504 observations concern firms 
that applied for a loan in the period.

We test our hypothesis using logit regression and re-test our findings by applying Heckman selection to address potential selection bias as well as different controls and different estimation techniques. In addition, we investigate the economic impact of creditor protection and judicial enforcement on credit access by examining the probability of obtaining credit in different contexts.

The results obtained are robust and suggest that the higher the creditor protection (high overall strength of the legal system, high property rights protection) and the better the judicial enforcement system (reduced costs, reduced time, and limited number of procedures), the lower the probability that the firms are credit constrained. Moreover, effective creditor protection and judicial enforcement reduce the firms' risk of only obtaining a proportion of the requested loan. Finally, we find that these variables have considerable economic impact: the probability of obtaining credit is up to $40 \%$ higher in countries with a more robust legal system.

Our findings contribute to research and practice on several levels. They support earlier empirical results by suggesting a positive relationship between both the quality of creditor protection and the quality of the judicial enforcement system and credit access. We extend the knowledge of the role of legal systems in credit access by highlighting the specific relevance of the number of procedures to the firms' ability to obtain credit. Thus, trials should not only be short and cheap, but also simple in order to enable banks to easily recover the loan in the event of default, and to encourage them to provide credit to firms. By investigating the role of both creditor rights and judicial enforcement, we develop a more comprehensive understanding of the legal system's traits that impact on the bank's lending decision. Due to our use of unique data on the firms' credit access, we further extend previous research by examining both firms that are credit constrained because they did not 
receive any credit at all and firms that are credit constrained because they only received part of the loan for which they applied. On the practical level, our findings provide considerable insight into the competitive advantages a firm may accrue due to easier access to finance, when it is located in an efficient legal environment. Those findings can inform both bank managers and the company management regarding their decision where to locate their activities.

The remainder of the paper is structured as follows. In Section 2, we present the results of previous research and develop the hypotheses. Section 3 discusses our dataset and the methodology and illustrates the variables used in the analysis. Descriptive statistics are presented in Section 4 and in Section 5, we present the econometric findings on the impact of the legal system on the credit provided to firms, as well as a set of robustness checks. In Section 6, we examine the economic impact, and Section 7 discusses the implications and concludes.

\section{Theoretical Research}

Firms tend to depend on bank debt in order to finance both their ongoing activities and growth. However, their ability to access bank credit is affected by the limited quantity and accuracy of information available (Berger and Frame 2007; Mason and Stark 2004), which impedes the assessment of their creditworthiness and can adversely affect access to credit (Moro, Fink, and Kautonen 2014; Petersen and Rajan 1994). In order to evaluate the risk associated with the firm, and reduce the risk of incurring future losses, banks aim to access additional information. However, even when the information asymmetry between the bank and the firm is reduced and the bank's assessment of the creditworthiness of the customer is facilitated, lending to firms remains an activity that involves a risk of a customer defaulting on the loan. Thus, the bank has to take into consideration the extent to which 
creditor rights are protected in determining what kind of loans and what kind of price and non-price terms it offers to firms, as creditor rights affect the bank's monitoring incentives and re-contracting costs that can be costly when creditor rights are poorly enforced (Bae and Goyal 2009).

Prior research suggests that firms benefit from a high level of creditor and property rights protection as well as rigorous law enforcement by accessing credit on more favourable terms. Qian and Strahan (2007) find that in countries with strong creditor protection, bank loans are associated with more concentrated ownership, longer maturities and lower interest rates. Bae and Goyal (2009) show that better property rights protection results in higher lending volumes, longer maturities and lower interest rates. The findings of both Laeven and Majnoni (2005) and Fabbri (2010) suggest that the quality of judicial enforcement affects interest rates. In addition, legal systems that bank managers perceive to be better are associated with a higher proportion of banks loans allocated to informationally opaque borrowers, such as small and medium-sized enterprises (Haselmann and Wachtel 2010), and a lower proportion allocated to large enterprises.

Earlier works further suggest a positive relationship between the quality of the legal system and credit access. Most of these works, however, use indirect measures of credit access. Jappelli, Pagano, and Bianco (2005) proxy credit access by investigating the proportion of overdraft credit lines and find that credit is less available in Italian provinces with longer trials or large backlogs of pending trials. The results of Deakin, Demetriades, and James (2010), who use the ratio of private bank credit to GDP to measure credit access, suggest that strengthened creditor protection in India leads to an increase in bank credit. Haselmann, Pistor, and Vig (2010) examine the effect of legal changes on credit access by using the total loan supply in a country. They find that the loan supply in transition economies increases after changes in collateral laws and bankruptcy laws. Adrianova et al. 
(2015) use the total loans to enterprises in Africa to investigate why banks refrain from lending. Their findings suggest that loan defaults impede bank lending when institutional quality is low. Liberti and Mian (2010) use collateral spreads to investigate how creditor rights and information sharing mechanisms affect credit constraints. In line with previous findings, their results indicate that stronger creditor rights and better information sharing mechanisms reduce collateral spreads and, as a consequence, improve credit access.

To the best of our knowledge, the only paper that employs data on the firms' perception of financing obstacles in order to examine the impact of the legal system on the firms' financing constraints is that by Beck, Demirgüc-Kunt, and Levine (2004). The authors provide evidence on the relationship between specific characteristics of a country's legal system, that is, the adaptability of the legal system and judicial independence, and firms' access to finance. Their results indicate that whereas cross-country variation in the adaptability of the legal system helps explain variations in financing obstacles, cross-country variation in the political independence of the judiciary does not help explain variations in financing obstacles. While this paper provides insight into the role of two specific traits of the legal system, it does not give a holistic picture of the relationship of both the quality of legal rules and the quality of judicial enforcement with firms' credit access. An investigation of both the quality of the legal rules and of judicial enforcement is required because previous research suggests that their quality can very independently (La Porta et al. 1998; Pistor, Raiser, and Gelfer 2000) and that high-quality laws cannot substitute for weak judicial enforcement (Pistor, Raiser, and Gelfer 2000). Thus, both high-quality laws (to protect the creditors' rights) and rigorous law enforcement are necessary in order to stimulate external finance. In addition to that, the quoted research does not differenciate between firms which face financial obstacles because they do not obtain any credit at all, and firms facing financial obstacles because they only receive part of the credit they applied for. However, in both cases 
firms will be credit constrained.

We aim to adress this gap by using data that enables us to evaluate firms that did not obtain any credit at all and firms that obtained only a part of the credit they applied for. Further, we examine how the strength of the legal rules and the rigour of judicial enforcement affects firms' ability to obtain credit.

In the context of lending relationships, a strong legal system is characterised by collateral and bankruptcy laws that protect the creditor if a borrower defaults. As a reputable legal environment increases the banks' recovery in the event of default, banks are expected to be more willing to provide credit on favourable terms (La Porta et al. 1997; Qian and Strahan 2007). Thus, the better the legal environment, the easier credit access for firms will be. This argument leads us to the following hypothesis:

H1: The greater the strength of the legal system, the lower the probability that firms are denied credit.

Bank lending decisions are also affected by the level of property rights protection (Bae and Goyal 2009). If private property is secured by clear laws enforced by the state, lenders can rely on the fact that they can enforce their rights quickly and efficiently if the borrower does not pay the principal and the interest on the date stipulated. A higher certainty of recovering the principal and the interest increases the banks' willingness to provide credit upfront and therefore reduces the firms' risk of being credit constrained. Based on these arguments, we propose the following hypothesis:

H2: The higher the level of property protection, the lower the probability that firms are denied credit. 
Access to finance for firms is also dependent on the quality of the judicial enforcement system. However, as the quality of judicial enforcement cannot be captured in a single index (Safavian and Sharma 2007), we investigate three different aspects that affect the enforcement of the law: (1) the number of procedures required to enforce a contract; (2) the time needed to resolve a dispute in the court; and (3) the cost of resolving a dispute in the court (court and lawyers' fees).

The number of procedural steps, that is, interactions between the parties or between the parties and the judge or court officer, required by law or commonly used, reflects the arduousness of the judicial enforcement system. This is because banks can be deterred from going to court if there are multiple procedural steps because the number of procedures implies additional effort and resources that have to be invested in recovering the credit. The greater the number of procedures necessary to recover the loan via legal action, the greater the risk the bank will face a loss if the borrower does not repay the debt and, therefore, the more reluctant the bank will be to grant credit to firms. Accordingly, we formulate the following hypothesis:

H3: The lower the number of procedures, the lower the probability that firms are denied credit.

Djankov et al. (2003) use the duration of dispute resolution in order to construct an index of procedural formalism of dispute resolution. They find that stronger procedural formalism is a strong predictor of longer duration of dispute resolution and that stronger procedural formalism is associated with lower-quality justice. Similarly, Safavian and Sharma (2007) stress that reforms in creditor rights have little impact on bank lending in 
countries and regions with very lengthy dispute resolution processes, but significant impact in countries and regions with rapid dispute resolution processes. The research by Fabbri (2010) suggests that even within a country, differences in the length of civil trials affect the cost of lending. Thus, the shorter the dispute resolution process in court, the more willing banks will be to grant credit to firms because they will be able to recover the loan more quickly. Based on this argument, we formulate the following hypothesis:

H4: The shorter the time to resolve a dispute in court, the lower the probability that firms are denied credit.

The quality of judicial enforcement is also determined by the accessibility to the enforcement system, which is reflected in the costs of accessing the court. Djankov et al. (2008) construct a measure of the efficiency of debt enforcement using the cost of the trial as well as the duration and the likely disposition of the assets. Their findings suggest that debt enforcement is highly inefficient and that this inefficiency correlates with underdeveloped debt markets. Moreover, Ahlquist and Prakash (2010) examine the relationship between foreign direct investment and the host countries' contract enforcement environment and find that foreign direct investment is associated with lower contract enforcement costs. Thus, enforcement costs seem to influence economic behaviour, and we expect that court fees and lawyers' fees, expressed as a percentage of the claim, influence the availability of loans for firms. The higher the costs for settling a dispute in court, the more reluctant banks will be to grant credit to firms. Against this backdrop, we propose the following hypothesis:

H5: The lower the costs incurred for settling a dispute at court, the lower the probability that firms are denied credit. 


\section{Data and Methodology}

\subsection{Data}

Our research relies primarily on the Survey on the Access to Finance of Enterprises (SAFE) conducted on behalf of the European Commission and the European Central Bank. It collects information about access to finance by firms within the European Union. The SAFE has been run on a given set of questions every six months since 2009 and systematically covers 11 Eurozone area countries (namely Austria, Belgium, France, Finland, Germany, Greece, the Netherlands, Ireland, Italy, Portugal and Spain).

Firms in the sample were randomly selected from the Dun \& Bradstreet business register. The sample was stratified by firm size class, economic activity and country. The sample was further constructed to offer approximately the same precision for micro-sized firms ( 1 to 9 employees), small firms (10 to 49 employees) and medium-sized firms (50 to 249 employees). A group of large firms (250 or more employees) was also included, which covers less than $10 \%$ of the total sample.

The sample sizes for each economic activity were selected to ensure adequate representation across the four largest activities: industry, construction, trade and services. Agriculture, forestry, fishing, financial intermediation, public administration and the activities of households and extra-territorial organisations, as well as bodies and holding companies, were excluded. Moreover, the sample sizes in the participating countries were selected based on representation at the country level. The person interviewed in each company was a top-level executive (Owner, General Manager, Financial Director or Chief Accountant). The questionnaire was translated into the local language. For the robustness checks we used a subset of the SAFE dataset for which we had detailed information on the financial statements of the firms. 
We integrated the data provided by the SAFE dataset with information from the quarterly Bank Lending Survey (BLS) run by national central banks on behalf of the European Central Bank. The BLS collects information about the banks' lending activities in the previous three months and the banks' propensity to lend in the next six months. It provides specific data on the banks' propensity to lend to large and small/medium firms as well as households. We used the data on large and small/medium firms for the previous three months as controls for the availability of credit in the market.

We also rely on the Eurostat database for general economic data. Eurostat is the statistical office of the European Union located in Luxembourg. Its task is to provide the European Union with statistics at the European level that enable comparisons between countries and regions. We used Eurostat to access homogeneous data on GDP growth, unemployment rates, inflation and the Herfindahl-Hirschman Index of bank concentration.

In order to access data on the quality of the legal system we used variables from two different sources: (1) the World Bank and (2) the Heritage Foundation. With regard to the World Bank, we use the Doing Business dataset. It offers data on business regulations from 2003 to the present and is considered highly reliable. With regard to the Heritage Foundation, we rely on the Index of Economic Freedom dataset.

All the datasets used provide information that is revised annually for each country included in our dataset.

\subsection{Methodology}

Since the dependent variable in our regressions is binary (bank loan obtained or not obtained by a specific firm), we approached the analysis using traditional logit regression (Hosmer and Lemeshow 2000). Because we rely on a panel dataset that is unmatched at firm level, we could not employ a fixed-effect panel regression that would have allowed consideration of the evolution of lending relationships through time at the firm level. 
We approached the analysis from two different perspectives. We estimated a set of different regressions, where we entered the different independent variables one by one. This approach avoided multicollinearity problems linked to the fact that our independent variables are significantly correlated with each other. We also re-estimated our models by including the interaction between variables that measure the legal system and those that measure the effectiveness of the judicial system. This allowed us to examine their joint effect.

In addition, we implemented a number of robustness checks. Since our approach might raise questions about the sample selection bias due to our use of a dataset that includes only firms that applied for a loan $(12,504$ out of 48,590), we re-estimated our hypotheses following Heckman's (1979) approach. We rely on the original dataset that contains 48,590 complete observations and employed the binary response model with sample selection, where the dependent variable indicates whether the firm applied for a loan - an approach similar to Piga and Atzeni (2007) and Piga and Vivarelli (2004). The identification of the selection equation requires at least one variable that determines the demand for a loan, but is irrelevant in the regressions. We found good candidates in the following variables: (1) the change in the turnover of the firm, since growing firms are more likely to need additional finance and therefore to apply for a loan, even if this does not mean that they will be successful; (2) the change in the profit of the firm, since more profitable firms are less likely to apply for a loan, as they can use their profit to finance their activities (Myers and Majluf 1984); and (3) the firm's independence, since firms that belong to a group are less likely to apply for a loan because they can rely on finance provided by the holding company or other group companies. All variables described above affect the firm's decision on whether to apply for a loan, but should not affect the probability that the lender will decide to provide the requested finance to the firm. We also ran alternative selection models and always obtained results very similar to those obtained with the model presented in the analysis section. 
Second, to reveal the joint role of these variables, we examined the opportunity to generate a construct representing the latent variable weakness of the legal system. To generate the construct, we first used confirmatory factor analysis to examine whether one factor could be extracted from our variables. Then, we used four out of five variables to generate the factor, which we defined as legal system weakness. We then re-estimated the original specification entering the factor instead. We estimated the regression according to both the basic logit regression and the Heckman selection process.

Third, we retested the specification using a different set of variables. The European Central Bank compiles a dataset that contains additional and more detailed variables, namely financial figures for the surveyed firms. The financial statements are extracted from the Amadeus Bureau Van Dijk database. Thus, we retested the hypotheses by using the same independent variables but a different set of controls comprising profitability ratios, liquidity ratios, and leverage ratios, that is, variables that typically proxy the risk of the firm.

Because we rely on data collected during a crisis, our results might merely reflect the increased importance of the judicial system for credit access. Because not all countries in our sample were affected by the financial crisis in the same way, we re-estimated our specifications by including only the countries that were hit by the crisis very marginally (namely Austria, France, Finland, Germany and the Netherlands). Then we repeated our estimate by including the interaction between a dummy that identified countries marginally affected by the crisis and our variables of interest. If the roles of legal environment and judicial effectiveness were not affected by the crisis, we should not have seen any change in the results with respect to our original regression.

We also re-estimated our models using sampling weights where the weights, originally included in the survey, were applied to adjust the sample to make it representative of the frame from which the sample was drawn. Moreover, because the original estimation of 
the standard errors can suffer from clustering of errors at the country level, we re-estimated our specification using robust estimates of the standard errors. We also checked whether the results could be affected by the way in which we defined the independent variable. To do so we used a different definition of the quality of the judicial system (i.e. a dummy that identifies protective vs non-protective and effective vs non-effective contexts). In addition, we checked whether the results were affected by the estimation approach used. In order to examine such potential issues, we re-estimated the regressions using probit estimation. We also retested our regressions with a bootstrap estimation of the standard errors (Efron and Tibshirani 1998).

\subsection{Dependent Variables}

The SAFE survey includes a question to firm managers on whether their firm obtained the credit it applied for in the last six months. We use the answer to this question (the firm obtained all the credit requested $=1$; the firm did not obtain the credit $=0$ ) as a dependent variable.

In order to pursue some of the robustness checks, we also examined whether the firms were only partially constrained. In this case, we used as a dependent variable whether the firm obtained the bulk of the loan it applied for, that is, more than $75 \%$ (the firm obtained the bulk of the credit $=1$; otherwise $=0$ ). We also used the answer to the question on whether the firm obtained less than $75 \%$ of the credit requested (the firm obtained less than $75 \%=1$; otherwise $=0$ ) to investigate whether the firm obtained only a fraction of the credit it originally applied for.

\subsection{Independent Variables}

We used different independent variables for each hypothesis tested. We examined the strength of the legal rights (H1) by using the Strength of Legal Rights Index (STRENGTH) as computed by the World Bank. The index measures the degree to which collateral and 
bankruptcy laws protect the rights of borrowers and lenders and therefore facilitate lending. The index ranges from 0 to 10 , with higher scores indicating better legal protection and therefore a set of laws that is better designed to expand access to credit. We collected the rating for each year considered and for each country in our sample. The variable is country variant but time invariant for the years considered.

We argue that the higher the level of property protection, the lower the probability that firms are denied credit $(\mathrm{H} 2)$. In order to test this hypothesis, we relied on the Index of Economic Freedom as computed by the Heritage Foundation by using the variable Property Rights (PRO_PROTECT). This variable measures the ability of individuals to accumulate private property, secured by clear laws that are fully enforced by the state. Hence, it measures the degree to which a country's laws protect private property and the degree to which its government enforces those laws. It also assesses the likelihood that private property will be expropriated. The index ranges from 0 to 100: the more solid the legal protection of property is the higher the country's score. Again in this case, the variable is country variant but time invariant for the years considered.

In order to test the impact of the number of procedural steps involved in a commercial dispute (H3) we used the data provided in the Doing Business dataset published by the World Bank (N_PROCEDURES). The World Bank defines a procedural step as any interaction, required by law or commonly used in practice, between the parties or between them and the judge or court officer. Other procedural steps, internal to the court or between the parties and their counsel are also counted. Procedural steps include filing and serving the case, assigning the case to a judge, the trial and judgment and the steps necessary to enforce the judgment. The variable is country variant and is time variant (but with only minor changes) in Italy, Spain and Portugal.

Our fourth hypothesis argues that the longer the time required to resolve a dispute, the 
higher the probability that firms are denied credit. Again, we rely on the Doing Business dataset and use the variable that records the average time needed to resolve a dispute in calendar days (TIME). The time is counted from the moment the plaintiff decides to file the lawsuit in court up until payment is made. It includes both the days when actions take place and the waiting periods between them. The variable is country variant and it is time variant (but with only minor changes) in Greece and Ireland.

In our fifth hypothesis, we suggest that the costs for settling a dispute in court affect the probability that firms are denied credit. In this case we used the variable that reflects the costs incurred as a percentage of the claim (COST_PERC) as computed in the Doing Business dataset. The variable includes three types of costs: court costs, enforcement costs, and average lawyers' fees. Court costs include all court costs that the plaintiff must advance to the court, regardless of the final cost to the plaintiff. Enforcement costs are all costs that the plaintiff must advance to enforce the judgment through a public sale of the opponent's assets. Average lawyers' fees are the average fees charged by a local lawyer to represent the plaintiff. The variable is country variant and is time variant (but with only a minor change) in the Netherlands alone.

\subsection{Controls}

We include a set of variables to control for the firm characteristics, the moment in time when the data were collected, the country and the economic context. In terms of firm characteristics, the SAFE dataset provides some information about the size of the firm by grouping the firms into four categories: micro, small, medium and large. We use three dummy variables that identify micro (MICRO), small (SMALL) and medium-sized (MEDIUM) firms. Our expectation is that larger firms are less likely to face a rejection because they are perceived as more secure and successful.

In addition, the SAFE dataset clusters the firms according to four age categories: 
younger than two years, between two and five years, between five and nine years and older than nine years. We used the 2_YEARS, 2_5_YEARS, and 5_9_YEARS dummy variables to identify the age group for each observation. According to previous research we expect older firms to be more likely to be successful when they apply for a loan (Berger and Udell 1995; Petersen and Rajan 1994): older firms have consolidated their reputations and that can be helpful when the banks have to make lending decisions (Martinelli 1997).

We also controlled for the financial strategy pursued by the firm by taking into consideration the different sources of finance used during the last period. We used dummies identifying whether the firm had used trade credit (TRADE_CREDIT), leasing (LEASING), retained earnings (RET_EARNINGS) or had raised additional equity (EQUITY) in the last period.

As explained above, in two cases the independent variables are time invariant at the country level and in the other cases the variability is very minor and only for a few countries. Thus, they present a very high correlation with the country. As a consequence, we did not include any control for the country that would have raised collinearity issues. However, we considered a set of country specific and time varying macroeconomic variables to capture the macroeconomic context in which firms operate.

Specifically, we controlled for the change in the gross domestic product (GDP), inflation rate (INFLATION) and overall unemployment rate (UNEMPL_OVERALL) for each country and each half-year. These data were obtained from the Eurostat dataset. Moreover, we accounted for the overall financial context by using the European Central Bank's BLS coefficients for small/medium and large firms (BLS). Because the BLS index is not available for all countries included in the analysis, we used the average index, when it was not available in a very limited number of cases and for smaller countries. Additionally, we considered the structure of the financial industry by using the Herfindahl-Hirschman 
Index of bank concentration (HHI) in each country because previous research suggests bank competition influences credit access (Carbó-Valverde, Rodríguez-Fernández and Udell 2009; Neuberger, Pedergnana and Räthke-Döppner 2008).

The dataset provided unmatched observations for eight semesters, and therefore we used seven dummies identifying the semester when the observation was collected.

In the regressions based on the Heckman selection process, we employed a categorical variable (CHANGE_TURNOVER) to identify whether the turnover reduced (-1), was stable $(0)$ or grew $(+1)$ in the period considered. The same approach was applied to profit (CHANGE_PROFIT). Regrettably, the standard SAFE dataset does not provide any information about the monetary value of turnover or profit. These two variables and also a dummy variable that measures whether the firm belongs to a group or not (INDEPENDENT) are expected to affect the decision to apply for a loan.

In the regressions that comprise the financial figures, we exploited a newly compiled dataset that augments the responses of the firms to SAFE with their detailed annual balance sheet and profit and loss information (Ferrando and Mulier 2013). Survey data for a given year are matched with balance sheet data of the year prior to the survey year. The rationale is that these are the most recent balance sheet data that firms had available to convince financial intermediaries to provide them external finance. This dataset contains 38,328 observations collected in the period 2009-2012 (Waves 3 to 9), 6,081 of which concern firms that applied for a loan. It includes detailed information about the firms' financial statements derived from the Amadeus Bureau Van Dijk database. For our analyses we used financial leverage, financial pressure, profit margin and collateral. These variables are most commonly used in the literature for explaining the determinants of financial constraints and defined as follows. Financial leverage (FIN_LEV) equals the ratio of financial debt (i.e. the sum of short-term and long-term debt) to total assets and indicates the degree to which the firm is indebted. We 
expect the relationship between financial leverage and credit constraints to be negative, as a large amount of debt on the balance sheet might make it difficult or costly for the firm to obtain additional funding. Financial pressure (FIN_PRES) is computed as a ratio of interest payments to earnings before interest payments, tax, depreciation and amortisation (EBITDA). If the ratio is high, the firm pays a significant amount of interest, either because it is too indebted or because it pays a high rate of interest on the existing debt. In either case, banks will be less likely to grant credit. Profit margin (PRO_MAR) equals the ratio of operating profits/losses to turnover and is a proxy for the profitability of the firm. If the profit margin is high, firms will be more likely to obtain credit because high profitability increases the probability that they will be able to repay their loan. Collateral (COLL) is the ratio of fixed assets to total assets. We expect the probability of obtaining credit to increase, if the ratio's value is high, as collateral is available to secure the loan repayment.

As an additional robustness check, we included the ratio of EBITDA to the difference of financial debt and cash holdings. The inclusion of this additional control variable results in a dataset of 6,081 observations of firms that applied for credit. We expect this ratio to be positively associated with the probability of obtaining credit, as a higher ratio suggests that the firm will be able to repay its debt quicker and will therefore be more likely to obtain a loan.

\section{Descriptive Statistics}

The dataset we used contains 48,590 complete observations from 11 countries for the period between the first semester of 2009 and the second semester of 2012 . The dataset was reduced to 12,504 observations by excluding firms that did not apply for a loan. The difference can be attributed to firms that either did not need finance (and therefore did not apply for a loan) or were discouraged from applying for a loan (i.e. firms that needed a loan 
but did not submit an application because they thought that it would be rejected). Figure 1 reports the percentage of firms having applied for a loan (lines) and of those that were successful (bars) as a percentage of all firms in the sample. These percentages vary considerably across countries and over time.

\section{FIGURE 1}

Table 1A reports summary statistics for the overall dataset and for each country, table 1B shows the data for the firms that applied for a loan. There are no missing countries in any wave considered in the sample.

TABLE 1A

TABLE 1B

In our sample the majority of firms are either micro or small and only $7.5 \%$ of them are classified as large. Three quarters of the firms in the sample are independent, $76 \%$ are more than nine-years old. Overall, the majority of firms in the sample are small, independent and well established. Only about one-third of the firms enjoyed an increase in turnover (34\%), whereas $28 \%$ did not experience any change and $38 \%$ found their turnover reduced in the relevant period. More than $45 \%$ experienced reduced profits, whereas only $27.3 \%$ enjoyed an increase. The statistics can be explained by the fact that the observations were made in the period between 2009 and 2012, thus falling into a period of overall economic stagnation. In terms of financing, firms appear to use leasing and trade credit quite 
intensively. Retained earnings are used by $32 \%$ of the firms. The BLS index is +5.09 , suggesting a reduction in credit availability, as positive values of this index are associated with a contraction of the credit provided by the banking system. The datum is in line with the more conservative lending policies pursued by the banks after the 2008 financial crisis and the introduction of the more stringent Basel III rules.

The coefficient that measures the strength of the legal system is rated between three (collateral and bankruptcy are not very well designed to expand access to credit; e.g. Italy, Portugal) and nine (collateral and bankruptcy are well designed to expand access to credit; e.g. Ireland). The property rights protection index reaches values between 50 (inefficient court system which is subject to delays; e.g. Italy) and 90 (private property is guaranteed by the state and the court system is efficient; e.g. Finland). The number of procedural steps involved in a commercial dispute ranges from 21 (e.g. Ireland) to 41 (e.g. Spain), whereas the time required to resolve a dispute is between 235 days (e.g. Finland) and 1,210 days (e.g. Italy). The costs of the claim range from $13.3 \%$ of the claim (e.g. Finland and Portugal) up to $29.9 \%$ of the claim (e.g. Italy).

Moving from the overall dataset to the subsample that contains only firms that actually applied for a loan (12,504 observations), the distribution of firm dimension is very similar to that of the overall sample: the majority of the firms are either micro $(24 \%)$ or small (34\%), with nearly one-third medium-sized firms (31\%). Large firms account for $11 \%$ of the subsample. Almost two-thirds of the firms (64\%) experienced a reduced or stable turnover during the period considered. Only $27 \%$ of them enjoyed an increase in profit. In terms of financing, the firms rely on trade credit and leasing ( $43.8 \%$ and $42.9 \%$ respectively). Interestingly, firms that apply for a loan appear to rely more on alternative sources of finance because they are around 10\% more likely to use trade credit and 9\% more likely to rely on leasing. We also test for differences in the characteristics of the firms between the overall 
sample and the subsample. However, in terms of firm age, firm dimension and firm performance (change in turnover and change in profit) there are no significant differences.

\section{Results}

The results are reported in Table 2. The first regression (Specification A) considers only the controls. Subsequently, we entered the independent variables one at a time. This allowed us to examine the impact of each legal system variable by comparing the other regressions to Specification A.

TABLE 2

Specification $\mathrm{A}$ is significant and $\mathrm{R}^{2}$ is 0.0634 . The size of the firm affects its access to credit: the bigger the firm, the less adversely affected is its access to credit. The same logic applies to the age of the firm: as the age class increases, the negative impact of age on credit access reduces, which suggests a relative lower probability of an application for credit being rejected. Different sources of finance negatively affect credit access: equity seems to be the strongest alternative to a loan, whereas leasing is not significant. As expected, the BLS index is negatively related to credit access: the less prone banks are to lend, the less likely firms are to be successful with loan application. Economic expansion (GDP) is positively related to credit access, whereas unemployment is negatively related.

Specification B includes the strength of the legal system (STRENGTH) and is significant. $\mathrm{R}^{2}$ improves to 0.0689 . This implies that the variable improves the variance explained by $7.98 \%$ with respect to the basic regression. There is no change in the significance level of the controls. Only INFLATION, which was not significant in Specification A, proves significant and positively related to obtaining credit. The dependent 
variable STRENGTH is highly significant and has the expected sign: the stronger the legal system, the higher the probability that a bank lends to the firm. Thus, H1 is confirmed.

Specification $\mathrm{C}$ allows for an investigation of the role of property protection (PRO_PROTECT). The specification is highly significant $(\mathrm{p}<0.0001) . \mathrm{R}^{2}$ is at 0.0664 , suggesting a limited contribution of the variable in explaining the overall variance. There is no change in the significance level of the controls except for LEASING, which is not significant. The dependent variable is significant at 0.001 and has the expected sign: the stronger the protection of property rights, the greater the probability that a bank lends to firms. Hence, $\mathrm{H} 2$ is also confirmed.

Specification D introduces the number of procedures (N_PROCEDURES). It is highly significant $(\mathrm{p}<0.0001)$. $\mathrm{R}^{2}$ improves to 0.0639 , that is, by a mere $0.78 \%$ on Specification A. This suggests that the number of procedures explains only a small proportion of the variance. There is no change in the significance level of the controls except for INFLATION, which is not significant. RET_EARNINGS and BLS are significant at 0.01. The dependent variable N_PROCEDURES is highly significant at 0.01 and has the expected sign: the higher the number of procedures the plaintiff incurs, the lower the probability that a bank grants credit to the firm. For that reason, H3 is also confirmed.

Specification E introduces the time (days) needed in order to resolve a dispute (TIME). The specification is highly significant $(\mathrm{p}<0.0001)$. The measured $\mathrm{R}^{2}$ improves to 0.0729 , that is, by $13.03 \%$ on Specification A. Interestingly, there are no changes in the significance level of the controls except for LEASING (which is significant, even if only at 0.10), GDP (which is not significant) and HHI (which is highly significant). The dependent variable TIME is significant at 0.01 and has the expected sign: the longer the time required to resolve a dispute, the less probable it is that a bank lends to firms. Thus, $\mathrm{H} 4$ is also confirmed. 
Specification F considers the cost of a legal proceeding as a percentage of the claim (COST_PERC). This specification is also highly significant $(\mathrm{p}<0.0001) . \mathrm{R}^{2}$ improves to 0.0732 and is the highest of all the regressions presented. Interestingly, there are no changes in the significance level of the controls except for GDP, which, in this case, is significant. The dependent variable COST_PERC is significant at the 0.01 level and has the expected sign: the higher the costs incurred in resolving disputes, the lower the probability that a bank grants credit to the firm. H5 is therefore also confirmed.

To further investigate the relationships, we tested the boundary conditions of our results. Doing so involved accounting for the possibility that judicial enforcement could also amplify or mitigate the effect of creditor rights in addition to the direct impact of creditor rights and judicial enforcement on the likelihood of obtaining credit. Higher costs, longer durations, and greater complexity with regard to the number of legal procedures are likely to adversely affect strong creditor rights, as they make it more difficult for a bank to enforce a legal claim if a borrower defaults. At the same time, poor creditor rights are likely to severely limit the benefits of cheap, fast, and simple judicial enforcement because the collateral and bankruptcy rights granted do not offer a reasonable chance that the court will decide in the bank's favour. In order to examine this aspect we interacted the judicial enforcement variables with the creditor protection variables, an approach similar to that of Safavian and Sharma (2007). Since our original judicial enforcement variables measured the ineffectiveness of the judicial enforcement system, we first reverse coded them and then renamed them (TIME became SPEED, COST_PERC became CHEAP and N_PROCEDURE became SIMPLE). The action ensured they pointed in the same direction as the creditor protection variables. Subsequently, we estimated six regressions, each of which included one creditor protection variable, one judicial enforcement variable, and their interaction. This approach allowed us to examine how SPEED, CHEAP and SIMPLE interacted with 
STRENGTH and PRO_PROTECT. Tables 3 and 4 report our findings.

TABLE 3

TABLE 4

Our results support the argument that both creditor rights and judicial enforcement affect credit access. With regard to the time required to resolve a dispute, the interaction of property rights protection and speed increases the probability of obtaining credit. In this case, the interaction substitutes for both property rights protection and speed. The same is true with regard to court and attorney costs. However, different results emerge with regard to the number of procedures, as property rights protection and reduced bureaucracy in court prevail over their joint effect by substituting it. Very similar results are obtained for the strength of the legal system: the interaction of the strength of the legal system with the time required to resolve a dispute and speed facilitates credit access, whereas the strength of the legal system and the number of procedures in disputes prevail over their interaction effect. Overall, the additional analyses lent further support to the important role of both creditor protection and judicial enforcement in granting credit.

\subsection{Robustness Checks}

The analysis presented so far provides clear results. Nevertheless, some additional robustness checks are needed before making any generalisations.

The first robustness check investigates if our results are affected by the sample selection bias. In order to deal with this issue, we re-estimated the regressions by relying on the Heckman sample selection model (Heckman 1979). We modelled the selection process 
using variables that measured the change in turnover, the change in profit and whether the firm belonged to a group. The results, resulting from the use of a Heckman probit estimation, are reported in Table 5. We also ran alternative selection models and always obtained results very similar to those presented in Table 5. Specifically, no changes in sign and significance level emerged.

\section{TABLE 5}

All specifications were significant. In addition, there were no major changes in the sign and the significance level with respect to the regression presented in Table 2: with regard to firm dimension, the variable MEDIUM proved not to be significant in Specifications $\mathrm{C}$ and D in the Heckman selection specification (it was formerly significant, but borderline). RET_EARNINGS was less significant in the Heckman selection than it used to be, whereas LEASING was more significant. From the general environment point of view there were minor changes in BLS, GDP (which became significant only at 0.05 for Specification B) and in INFLATION, which was not significant in Specification E. Interestingly, there are no changes in the sign and the significance level of the independent variables. In fact, the significance decreases slightly in the instance of the number of procedures (N_PROCEDURES). Overall, the results strongly confirmed all previous findings in terms of supporting the hypotheses.

The second robustness check investigated the joint effect of the independent variables. As it was not possible to enter all covariates in the regression at the same time due to multicollinearity problems, we developed a construct that we defined as weak legal system (WEAK_SYS) by incorporating the variables mentioned above t. This construct aims at measuring the overall weakness of the legal system. In order to set it up, we first reversed the 
STRENGTH and PRO_PROTECT in order to generate variables that measured the weakness of the legal system and the low level of property rights protection. Thus, all measures considered point in the same direction: the higher the value of our variables, the lower the quality of the legal system. Then, we implemented exploratory factor analysis. We obtained the highest Cronbach alpha of 0.6400 (which is acceptable) by considering only four of the five variables: STRENGTH, N_PROCEDURE, COST_PERC, and PRO_PROTECT. Accordingly, we decided to exclude TIME from our construct. Factor analysis suggested that one factor could be extracted, as only the first factor had an eigenvalue higher than 1 (namely 2.5868 ) and it explained $64.67 \%$ of the variance. All variables load on the factor at 0.46 or higher. The Kaiser-Meyer-Olkin measure of sampling adequacy is 0.62 , which is acceptable. Thus, we generated the score of the variable that measures the weakness of the legal system (WEAK_SYS) and entered it in the regression. The results are reported in Table 6 (logit regression) and Table 7 (Heckman selection). Moreover, in this case we ran alternative selection models and always obtained results very similar to those presented in the original regressions. Specifically, no change in the sign and significance level emerged.

\section{TABLE 6}

\section{TABLE 7}

The specification is highly significant $(\mathrm{p}<0.0001) . \mathrm{R}^{2}$ is 0.0684 , slightly higher than in Specification A. Interestingly, there are no major changes in the significance level of the controls. The dependent variable WEAK_SYS is significant at the 0.01 level and has the expected negative sign. The finding suggests that the legal system affects the availability of 
credit to firms: the weaker the legal system, the lower the probability that a bank lends to a firm. With regard to the Heckman selection, the specification is also significant. There are minor changes in the significance level of some controls, but there is no change in the significance level of the factor WEAK_SYS. The results provide additional support to our original findings: a legal system that is weak overall leads to a reduction in the lines of credit provided to firms.

We also re-estimated the models using the newly compiled dataset that, although smaller, contains a different set of controls, namely detailed financial figures and ratios based on the financial figures of a subsample of the surveyed companies. This approach has the advantage that we could objectively control for the financial position of firms when they applied for a bank loan. The results are reported in Tables 8 (basic model) and 9 (Heckman selection). For the Heckman model, we also ran alternative selection models and always obtained results very similar to those presented in the original regressions. In particular, no change in the sign and significance level emerges.

TABLE 8

TABLE 9

The empirical results show that firms with higher debt ratios and firms that are using a larger proportion of their profits to pay interest have a higher probability of being rejected. More profitable firms or firms with more collateral, in contrast, have a greater chance of obtaining a loan. As in the previous models, we further tested the role of the quality of the legal system by entering the variables characterising the legal system one by one. All the 
results of the baseline analysis using the logit model or through the Heckman sample selection model were confirmed.

As an additional robustness test, we substituted financial leverage with the ratio of EBITDA to the difference of financial debt and cash. The estimated coefficients are significant in all specifications and, more importantly, the results on the quality of the legal system are confirmed.

Since we rely on data collected during a crisis, our results might merely reflect the increased importance of the judicial system in access to credit. During this period, banks might have feared increases in defaults on loans, which could have raised the importance of well-functioning creditor rights and judicial enforcement. However, not all countries in our sample were affected equally by the financial crisis. We therefore first re-estimated our specifications by including only the countries that were hit by the crisis very marginally, that is, countries that did not face any sovereign debt problems or whose economy suffered only from minor setbacks and recovered quite quickly (namely Austria, France, Finland, Germany and the Netherlands). The regressions do not present major changes in the significance of the variables included. More importantly, there is no change in the significance level of the creditor rights and judicial enforcement variables: all five variables are significant and there is no change in the sign. Second, we generated a dummy variable that discriminated between countries that were only marginally affected by the financial crisis and countries that were severely affected. We then interacted this dummy with each of the creditor rights and judicial enforcement variables and re-estimated our models by including both the original and the interacted variables. Again in this case the original variables have the same sign and the same significance level. These results suggest that our main findings are not affected by the financial crisis.

We also retested our model using a set of different independent variables. We 
generated a dummy variable that measured whether the legal context is effective in enforcing the law (1) or not (0) by using the median values of each independent variable as thresholds. The dummy variables are always significant and have the same sign as in the original model (detailed results not reported here).

Moreover, we ran some econometric robustness checks. First, we re-estimated the regressions by using a different econometric approach, namely probit regression instead of logit regression. This allowed us to check whether our results are sensitive to the econometric approach used in our estimations. Detailed results are not reported here. Interestingly, there is no change in the significance and the sign of the variables entered in the regression. Second, we re-estimated the standard errors by using a bootstrap estimation of the standard errors (Efron and Tibshirani 1998). Again there is no change in the significance of the variables entered in the regressions. Third, we ran an additional robust check by estimating our basic regression and the Heckman selection model using sampling weights. SAFE provides weights to restore the proportions of the economic weight (in terms of number of employees) for every size, economic activity and country. Detailed results are not reported here, but there are no changes in the significance of our legal/judicial system variables. We also re-estimated the specification taking into consideration that errors can be clustered at the country level. In this case, we used a robust estimation of the standard errors. Again, detailed results are not reported here, but no changes emerged. Finally, we re-estimated the specification including dummy variables identifying the industries (detailed results not reported). Again, there are no changes with respect to our original findings.

Our robustness checks suggest that the original findings are robust to sample selection, alternative specifications, alternative independent variables and different estimation techniques. 


\section{Economic Impact}

So far our analysis shows that the creditor protection and judicial enforcement statistically affect the access to credit. However, we did not check the economic robustness and solidity of our results as well as their economic impact. In this section we will examine both aspects.

Our basic regressions look at firms that applied for a loan and discriminate between those that obtained the entire requested amount and those that did not obtain it. In fact, firms can be credit constrained when they obtain only a proportion of the requested credit. The impact of creditor rights and judicial enforcement is higher if it contributes to the reduction of any form of financial constraint (partial or total) by helping firms to obtain the entire requested loan. Thus, creditor rights and judicial enforcement should not only increase the probability of obtaining the total credit required, but should also reduce the probability that a firm obtains only a proportion of it. In order to examine this aspect, we re-estimated our regressions using two alternative dependent variables: whether the firm obtained the bulk of the credit requested $(>75 \%)$ and whether the firm obtained a lesser part of the credit requested $(<75 \%)$. According to our reasoning, STRENGTH and PRO_PROTECT have to be negatively related to both dependent variables because the stronger the legal system and the higher the property protection, the lower the probability of being granted only a proportion of the loan (be it a major or minor proportion). Similarly, N_PROCEDURE, COST_PERC, and TIME should be positively related to obtaining only a fraction of the loan because the greater the number of the procedures involved, the time spent in court and the cost of legal proceedings, the higher the probability that banks will grant only a proportion of the requested loan in order to reduce the risk incurred.

The results of the re-estimated regressions are reported in Tables 10 and 11 . We also re-estimated the regressions using the entire dataset and applying the Heckman selection. The 
results are not reported here. Nevertheless, no significant change emerged.

\section{TABLE 10}

\section{TABLE 11}

Our expectations find strong support in the cases of STRENGTH and PRO_PROTECT. In both the coefficient proves negative and statistically significant. Interestingly a decreasing trend emerges when we look at firms that are partially credit constrained: the coefficients in the regressions that rely on firms that obtained the bulk of the loan requested are greater than those for the sample of firms that obtained only a proportion of the loans requested.

Also in the case of COST_PERC and TIME, the results confirm our expectations when we compare the coefficients of the firms that obtain the entire amount of credit requested to those that obtained the bulk of it. However, the change in the coefficient between the two groups is very small and statistically not significant. Finally, for N_PROCEDURE our expectations are confirmed, but only when we compare the firms that obtained the loan with those that obtained only a minor proportion of it. Table 12 presents the trends in the coefficients (using odd ratios).

\section{TABLE 12}

The results suggest that creditor rights and judicial enforcement support access to the entire amount of credit also by reducing the risk that the firms can be partially constrained in 
accessing credit.

The final step of our analysis is to examine the economic impact of creditor rights and judicial enforcement. The results so far show that the legal system has a positive effect on the probability that a firm obtains the credit requested. However, it is important to examine the economic impact of such a statistically significant relationship. In order to do so, we estimate the probability of obtaining credit for each independent variable at their lowest and highest figure. For instance, with regard to the cost of the procedure, we estimated the probability of a firm in Italy obtaining credit (where the cost is $29.9 \%$ of the claim) and for a firm in Finland (where the cost is $13.3 \%$ of the claim).

The results are reported in Table 13.

\section{TABLE 13}

Turning to the strength of the legal system, the value of the variable in the dataset is between 3 (Italy) and 9 (Ireland). Our calculations show that a firm operating in a country with a very strong legal system (in our case Ireland, probability 0.7589 ) is almost $30 \%$ more likely to obtain the credit it applies for than a firm which operates in a country with weak legal system (Italy, probability 0.5870 ) and that this difference is statistically significant. With regard to property protection the difference is smaller (around 19\%), but nevertheless economically relevant ( 0.6026 vs 0.7172$)$ and statistically significant.

Both time and costs present very similar differences: the probability of getting access to the total credit requested is between $54 \%$ and $55 \%$ in a country with weaker law enforcement (in our sample Italy), while it is between $73 \%$ and $75 \%$ in a country where law enforcement is effective (in our sample Finland). The variable that generates the smallest differential in the probability to obtain credit is the number of procedures (the difference 
being below 9\%). However, the difference is statistically significant and economically relevant.

Finally, we re-estimated the probability of obtaining credit by using the factor WEAK_ENFORCEMENT. Interestingly enough, the country with the weakest enforcement capability appears to be Italy while the one with the strongest enforcement capability is Ireland. In the case of Italy, the probability of obtaining credit for the average firm is 0.5435 while for Ireland it is 0.7402 . The difference is statistically significant and economically relevant.

\section{Conclusion}

Our research suggests that strong creditor and property rights as well as a rigorous judicial enforcement system support the bank's lending decision favouring the provision of credit to firms. This is because better creditor protection makes it easier for banks to deal with borrower risk, as the probability of their recovering the loan in the face of a default increases. Thus, firms benefit from a high level of creditor protection and rigorous judicial enforcement due to higher probability of obtaining the external finance required for their ongoing activities or investments. These results proved robust against a set of econometric tests.

Our findings have considerable implications for both firms and banks. With regard to firms, our results suggest that a firm operating in a country with weak creditor protection and a low-quality judicial enforcement system can face a competitive disadvantage compared to a firm located in a country with strong creditor protection and a high-quality judicial enforcement system. This is because the firm faces more difficulties in accessing bank loans, which, in turn, constrains its development and growth, as alternative sources of finance, such as leasing and trade credit, cannot fill the financing gap (Beck, Demirgüc-Kunt, and 
Maksimovic 2008). Interestingly, we find differences of up to $30 \%$ in terms of the probability of obtaining credit among countries that are all member states of the European Union. The context (i.e. the single-market policies pursued in the European Union, such as the free exchange of goods or services and the freedom of establishment) implies that differences in the probability of obtaining credit may have considerable implications for firms located in countries where access to credit is more difficult because of weak creditor protection and poor judicial enforcement because they cannot be protected by trade barriers. The big differences in the probability of obtaining credit suggest that firms located in a weak legal environment may not only be adversely affected when they try to enter a foreign market, but might also struggle to maintain their local market share because of the competition from foreign firms. In addition, as the freedom of establishment facilitates the relocation of affected firms to another EU member state, differences in the legal system can also motivate firms to move to countries where the legal system allows for easier access to credit. Thus, the quality and efficiency of the legal system can have a considerable impact on a country's GDP growth and job creation. Our argument is in line with previous research, which suggests that the credit granted in a supportive legal environment is provided on more favourable conditions (Qian and Strahan 2007)and also to firms investing in intangible assets, or firms with highly volatile returns (Giannetti 2003). This aspect is even more important because there is some consistency at the country level in terms of creditor protection and judicial enforcement: Italy ranks last in four out of five dimensions, while Finland ranks at the top in three out of five dimensions.

With regard to banks, our results suggest that a bank that operates in a country with strong creditor protection and a high-quality judicial enforcement system enjoys a competitive advantage. This is because a bank operating in a country with strong creditor protection and a high-quality judicial enforcement system can be more confident that it will 
retrieve the loan if a borrower defaults than a bank operating in a country with weak creditor protection system and a low-quality judicial enforcement system. Our results are in line with previous findings at the macroeconomic level suggesting that the legal environment affects the development of debt markets (Djankov et al. 2008; La Porta et al. 1997) and that the development of debt markets affects economic growth (Levine 1998).

Our results have relevant policy implications for banks and firms. Improving the quality of the relevant law and law enforcement could facilitate credit access for firms. While we are not the first to come to the conclusion that better laws improve external debt financing, our evidence is very specific and direct because it is based on the firms' semiannual self-assessment of their financing situation. Second, our findings suggest that a judicial enforcement system that is characterised by short, cheap and simple proceedings creates favourable conditions for bank lending. Even though changing legal codes and improving the quality of the judicial enforcement system is difficult, the economic returns of such changes can be relevant as shown by our economic analysis.

Our research also contains some limitations. First, we examine only European firms because of the characteristics of the dataset used. It would be interesting to replicate the research in other areas in order to verify the robustness of the role played by different legal systems around the world. The enlargement of the dataset could also allow for an examination of whether the legal environment is equally relevant in developing and in developed economies. Second, our dataset is cross sectional, meaning we could not examine the impact of the legal system on a specific firm's loan request over time. However, we are confident that this aspect did not affect our results. Nevertheless, such an analysis could offer a more fine-grained understanding of the impact of legal systems.

Notwithstanding the limitations of the dataset and context, the study indicates that the effectiveness and efficiency of the law and the judicial enforcement system might play a 
more important role in lending relationships than has been acknowledged. 
References

Adrianova, S., B. Baltagi, P. Demetriades, and D. Fielding. 2015. "Why Do African Banks Lend so Little?" Oxford Bulletin of Economics and Statistics 77: 339-59.

Ahlquist, J S, and A Prakash. 2010. "FDI and the Costs of Contract Enforcement in Developing Countries.” Policy Sciences 43: 181-200.

Bae, K H, and V K Goyal. 2009. “Creditor Rights, Enforcement, and Bank Loans.” Journal of Finance 64: 823-60.

Beck, Demirgüc-Kunt, and Levin. 2004."Law and Firms’ Access to Finance."World Bank Policy Research Paper 3194

Beck, Thorstein, Asli Demirgüc-Kunt, and V. Maksimovic. 2008. "Financing Patterns around the World: Are Small Firms Different?” Journal of Financial Economics 89: 467-87.

Berger, Allen N, and Scott W Frame. 2007. "Small Business Credit Scoring and Credit Availability." Journal of Small Business Management 45 (1): 5-22.

Berger, Allen N, and Gregory F Udell. 1995. "Relationship Lending and the Lines of Credit in Small Firm Finance.” Journal of Business 68 (3): 351-81.

Carbó-Valverde, Santiago, Francisco Rodríguez-Fernández, and Gregory F Udell. 2009. “Bank Market Power and SME Financing Constraints.” Review of Finance 13: 309-40.

Deakin, S., P. Demetriades, and G.A. James. 2010. “Creditor Protection and Banking System Development in India.” Economic Letters 108: 19-21.

Diamond, Douglas W. 1984. "Financial Intermediation and Delegated Monitoring.” Review of Economic Studies 51 (3): 393-414.

Djankov, S, R La Porta, F Lopez de Silanes, and A Shleifer. 2003. “Courts.” Quarterly Journal of Economics 118: 453-517.

Djankov, S, R La Porta, F Lopez-de-Silanes, and A Shleifer. 2008. "The Law and Economics 
of Self-Dealing." Journal of Financial Economics 88: 430-65.

Efron, Bradley, and Robert T Tibshirani. 1998. An Introduction to the Bootstrap. Boca Raton (FL): Chapman and Hall CRC.

Esty, B C, and W L Megginson. 2003. “Creditor Rights, Enforcement, and Debt Ownership Structure: Evidence from the Global Syndicated Loan Market." Journal of Financial and Quantitative Analysis 38: 37-59.

Fabbri, D. 2010. "Law Enforcement and Firm Financing: Theory and Evidence.” Journal of the European Economic Association 8: 776-816.

Ferrando, A, and K Mulier. 2013. 'Firms' Financing Constraints: Do Perceptions Match the Actual Situation?" The Economic and Social Review 46 (1): 87-117.

Giannetti, M. 2003. “Do Better Institutions Mitigate Agency Problems? Evidence from Corporate Finance Choices. ." Journal of Financial and Quantitative Analysis 38: 185213.

Haselmann, R, K Pistor, and V Vig. 2010. “How Laws Affect Lending.” Review of Financial Studies 23 (2): 549-80.

Haselmann, R, and P Wachtel. 2010. "Institutions and Bank Behavior: Legal Environment, Legal Perception and the Composition of Bank Lending." Journal of Money, Credit and Banking 42: 965-84.

Heckman, James J. 1979. "Selection Bias as a Specification Error.” Econometrica 47 (1): $153-61$.

Hosmer, David W, and Stanley Lemeshow. 2000. Applied Logistic Regresson. Wiley Series in Statistics and Probability. New York: Wiley.

Jappelli, T, M Pagano, and M Bianco. 2005. "Courts and Banks: Effects of Judicial Enforcement on Credit Markets.” Journal of Money, Credit and Banking 37: 223-44. La Porta, R, F Lopez-de-Silvanes, A Shleifer, and R W Vishny. 1997. "Legal Determinants 
of External Finance." Journal of Finance 52: 1131-50.

. 1998. "Law and Finance.” Journal of Political Economy 106: 1113-55.

Laeven, L, and G Majnoni. 2005. "Does Judicial Efficiency Lower the Cost of Credit?" Journal of Banking and Finance 29: 1791-1812.

Levine, R. 1998. “The Legal Environment, Banks and Long-Run Economic Growth. .” Journal of Money, Credit and Banking 30: 596-613.

Liberti, J R, and A Mian. 2010. "Collateral Spread and Financial Development.” The Journal of Finance 65 (1): 147-77.

Martinelli, Cesar. 1997. "Small Firms, Borrowing Constraints, and Reputation,." Journal of Economic Behavior \& Organization 33: 91-105.

Mason, Colin, and Matthew Stark. 2004. "What Do Investors Look for in a Business Plan? A Comparison of the Investment Criteria of Bankers, Venture Capitalists and Business Angels.” International Small Business Journal 22 (3): 227-48.

Moro, Andrea, Matthias Fink, and Teemu Kautonen. 2014. "How Do Banks Assess Entrepreneurial Competence? Public Data vs. Voluntary Information Disclosure.” International Small Business Journal 35 (5): 525-44. doi:10.1177/0266242612458444. Myers, Stewart C, and Nicholas S Majluf. 1984. "Corporate Finance and Investment Decisions When Firms Have Information Investors Do Not Have.” Journal of Financial Economics 13: 187-221.

Neuberger, Doris, Maurice Pedergnana, and Solvig Räthke-Döppner. 2008. “Concentration of Banking Relationships in Switzerland: The Result of Firm Structure or Banking Market Structure?” Journal of Financial Services Research 33 (2): 101-26.

Petersen, Mitchell A, and Raghuram G Rajan. 1994. "The Benefits of Lending Relationships: Evidence from Small Business Data.” Journal of Finance 49 (1): 3-37. Piga, Claudio A, and Gianfranco Atzeni. 2007. "R\&D Investment, Credit Rationing and 
Sample Selection.” Bulletin of Economic Research 59 (2): 149-78.

Piga, Claudio A, and Marco Vivarelli. 2004. "Internal and External R\&D: A Sample Selection Approach." Oxford Bulletin of Economics and Statistics 66 (4): 457-82.

Pistor, K, M Raiser, and S Gelfer. 2000. "Law and Finance in Transition Economies.” Economics of Transition 8: 325-68.

Qian, J, and P E Strahan. 2007. "How Laws and Institutions Shape Financial Contracts: The Case of Bank Loans.” Journal of Finance 62: 2803-34.

Safavian, M, and S Sharma. 2007. "When Do Creditor Rights Work?” Journal of Comparative Economics 35: 484-508. 
Figure 1

Applications for bank loans and successful applications (over the preceding six months; percentage of respondents)

Loan obtained

Loan requested

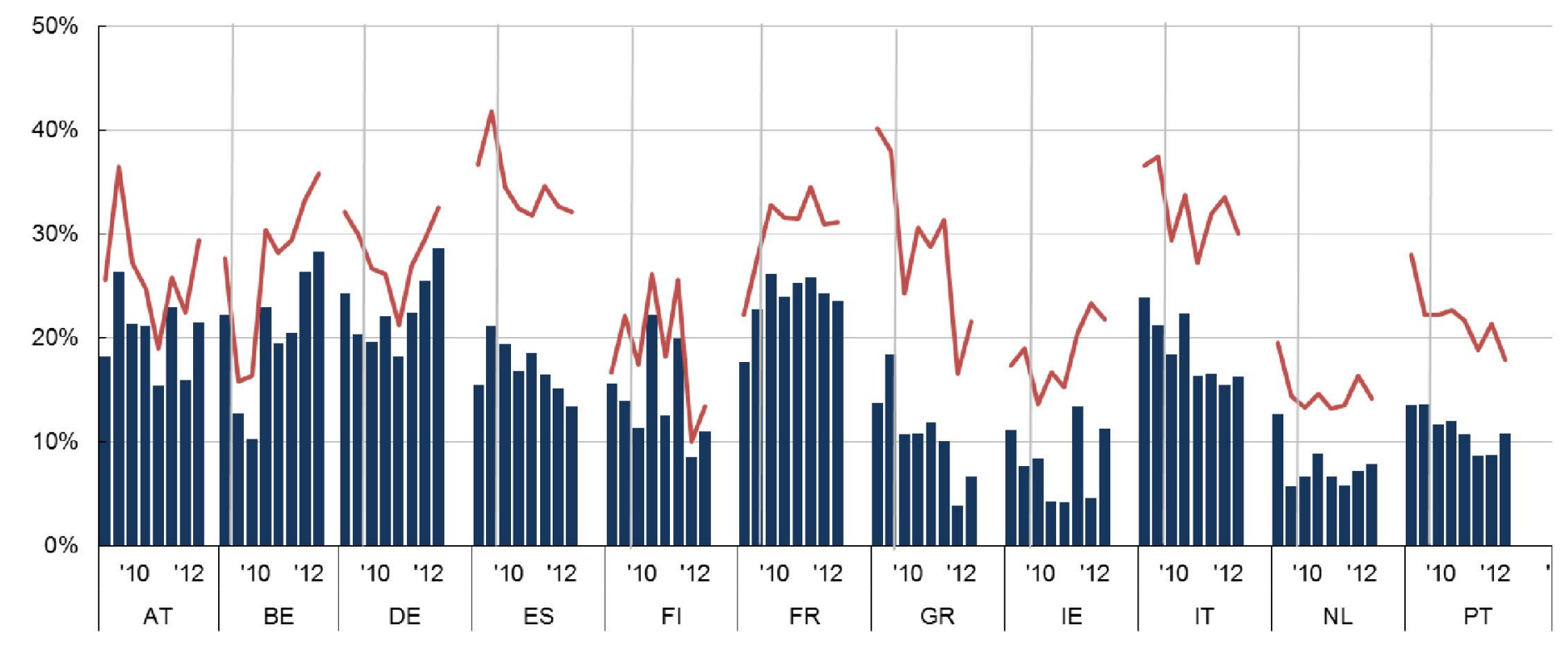




\section{Table 1A Basic Statistics - Overall Dataset}

Notes: Variables presented in the table include: dummy for bank loan application; dummy for bank loan obtained; dummies for firm size (micro, small, medium-sized and large firms); dummies for age (less than two years, two to five years, five to nine years, more than nine years); dummy for independent firms; change in turnover and in profit (reduction -1,

unchanged 0, increase 1); dummies for sources of finance (use of retained earnings, trade credit and leasing, increase in equity); Bank Lending Survey index; GDP growth; inflation rate; unemployment rate; Herfindahl-Hirschman Index of bank concentration; coefficients for strength of the legal system, property rights protection, time to resolve a dispute, costs to settle a dispute and number of procedural steps.

\begin{tabular}{|c|c|c|c|c|c|c|c|c|c|c|c|c|c|c|c|c|c|c|c|c|c|c|c|}
\hline & \multirow{2}{*}{\multicolumn{7}{|c|}{ Overall }} & & & & & & & & & & & & & & & \\
\hline & & & & & & & & & \multicolumn{4}{|c|}{ Belgium } & \multicolumn{3}{|c|}{ Germany } & \multicolumn{4}{|c|}{ Spain } & \multicolumn{4}{|c|}{ Finland } \\
\hline & & obs & \multicolumn{2}{|l|}{48590} & \multicolumn{4}{|c|}{2724} & \multicolumn{4}{|c|}{2813} & \multicolumn{3}{|c|}{$\begin{array}{c}\text { Germany } \\
6989\end{array}$} & \multicolumn{4}{|c|}{7369} & \multicolumn{4}{|c|}{$\frac{\text { Finland }}{2631}$} \\
\hline & & \multirow[b]{2}{*}{ Mean } & \multicolumn{2}{|l|}{$\begin{array}{l}40370 \\
\text { Std. }\end{array}$} & \multicolumn{4}{|c|}{ Std. } & \multicolumn{4}{|c|}{ Std. } & \multicolumn{3}{|c|}{ Std. } & \multicolumn{4}{|c|}{ Std. } & \multirow[b]{2}{*}{ Mean } & \multirow[b]{2}{*}{ Std. Dev. } & \multirow{2}{*}{\multicolumn{2}{|c|}{ Min }} \\
\hline & & & Dev. & Min Max & Mean & Dev. & $\operatorname{Min} M$ & & Mean & Dev. & $\operatorname{Min}$ & $\operatorname{Max}$ & Mean & Dev. & Min Max & Mean & Dev. & Min & $\operatorname{Max}$ & & & & \\
\hline Loan Requested & Whether the firm applied for a loan & 0,257 & 0,437 & $\begin{array}{ll}0 & 1\end{array}$ & 0,221 & 0,415 & 0 & 1 & 0,253 & 0,435 & 0 & 1 & 0,230 & 0,421 & $\begin{array}{ll}0 & 1\end{array}$ & 0,337 & 0,473 & 0 & 1 & 0,155 & 0,362 & 0 & \\
\hline Loan Obtained & Whether the firm obtained a loan & 0,169 & 0,375 & 0 & 0,182 & 0,386 & 0 & 1 & 0,194 & 0,395 & 0 & 1 & 0,183 & 0,386 & 0 & 0,171 & 0,377 & 0 & 1 & 0,130 & 0,337 & 0 & \\
\hline Micro & Micro firms & 0,334 & 0,472 & 0 & 0,344 & 0,475 & 0 & 1 & 0,386 & 0,487 & 0 & 1 & 0,300 & 0,458 & 0 & 0,310 & 0,462 & 0 & 1 & 0,398 & 0,490 & 0 & \\
\hline Small & Small firms & 0,335 & 0,472 & 0 & 0,348 & 0,477 & 0 & 1 & 0,383 & 0,486 & 0 & 1 & 0,312 & 0,463 & 0 & 0,313 & 0,464 & 0 & 1 & 0,391 & 0,488 & 0 & 1 \\
\hline Medium & Medium firms & 0,257 & 0,437 & 0 & 0,233 & 0,423 & 0 & 1 & 0,183 & 0,387 & 0 & 1 & 0,293 & 0,455 & 0 & 0,291 & 0,454 & 0 & 1 & 0,174 & 0,380 & 0 & \\
\hline$<2$ years & Firms younger than 2 years & 0,021 & 0,142 & 0 & 0,040 & 0,195 & 0 & 1 & 0,013 & 0,112 & 0 & 1 & 0,018 & 0,133 & 0 & 0,008 & 0,091 & 0 & 1 & 0,014 & 0,116 & 0 & \\
\hline 2 and 5 years & Firms b & 0,080 & 0,272 & 0 & 0,069 & 0,253 & 0 & 1 & 0,078 & 0,268 & 0 & 1 & 0,086 & 0,280 & 0 & 0,074 & 0,262 & 0 & 1 & 0,049 & 0,216 & 0 & \\
\hline 5 and 9 years & Firms between 5 and $9 y$ & 0,135 & 0,342 & 0 & 0,123 & 0,328 & 0 & 1 & 0,127 & 0,333 & 0 & 1 & 0,124 & 0,330 & 0 & 0,136 & 0,343 & 0 & & 0,120 & 0,325 & 0 & \\
\hline Independent & Whether the firm is independent & 0,770 & 0,421 & 0 & 0,187 & 0,791 & -1 & 1 & 0,076 & 0,829 & -1 & 1 & 0,143 & 0,801 & -1 & 0,296 & 0,824 & -1 & 1 & 0,119 & 0,824 & -1 & \\
\hline Change_turnover & Change in turnover in the last semester & 0,038 & 0,846 & -1 & 0,034 & 0,812 & -1 & 1 . & 0,066 & 0,843 & -1 & 1 . & 0,012 & 0,826 & -1 & 0,399 & 0,795 & -1 & 1 & 0,005 & 0,814 & -1 & \\
\hline Change_profit & Change in profit in the last semester & 0,183 & 0,834 & -1 & 0,390 & 0,488 & 0 & 1 & 0,229 & 0,420 & 0 & 1 & 0,448 & 0,497 & 0 & 0,318 & 0,466 & 0 & 1 & 0,493 & 0,500 & 0 & \\
\hline Ret_earnings & Use of retained $\mathrm{e}$ & 0,320 & 0,467 & 0 & 0,235 & 0,424 & 0 & 1 & 0,256 & 0,437 & 0 & & 0,163 & 0,369 & 0 & 0,427 & 0,495 & 0 & 1 & 0,518 & 0,500 & 0 & \\
\hline Trade_credit & Use of trade credit & 0,343 & 0,475 & 0 & 0,434 & 0,496 & 0 & 1 & 0,229 & 0,420 & 0 & 1 & 0,504 & 0,500 & 0 & 0,296 & 0,457 & 0 & & 0,394 & 0,489 & 0 & \\
\hline Leasing & Use of leasing & 0,339 & 0,473 & 0 & 0,080 & 0,272 & 0 & 1 & 0,068 & 0,252 & 0 & & 0,129 & 0,335 & 0 & 0,026 & 0,159 & 0 & 1 & 0,072 & 0,259 & 0 & \\
\hline Equity & Increase in equity & 0,061 & 0,240 & 0 & 0,733 & 0,443 & 0 & 1 & 0,712 & 0,453 & 0 & 1 & 0,790 & 0,408 & 0 & 0,788 & 0,409 & 0 & & 0,737 & 0,441 & 0 & \\
\hline BLS & Bank Lending Survey index & 5,091 & 10,069 & -14 & 1,002 & 3,812 & -10 & 20 & 5,803 & 4,485 & $-1,1$ & 17 & 1,239 & 6,573 & -5 & 1,693 & 5,693 & -5 & 17 & 5,859 & 4,181 & $-1,125$ & \\
\hline GDP & Change in Gross Domestic Product & 0,507 & 2,905 & $-8,5$ & 1,113 & 2,027 & $-3,8$ & 2,8 & 0,763 & 1,645 & $-2,8$ & 2,3 & 0,694 & 3,637 & $-5,1$ & 1,406 & 1,551 & $-3,8$ & 0,1 & 0,749 & 3,225 & $-8,5$ & \\
\hline Inflation & Inflation rate & 1,912 & 1,204 & $\begin{array}{ll}-1,7 & 4,7\end{array}$ & 2,415 & 1,046 & 0,4 & 3,6 & 2,471 & 1,022 & 0 & 3,4 & 1,460 & 0,884 & $0,2 \quad 2,5$ & 1,793 & 1,241 & $-0,2$ & 3,1 & 2,798 & 0,715 & 1,6 & \\
\hline Unempl_overall & Unemployment rate & 10,982 & 5,771 & $\begin{array}{ll}3,25 & 25,7\end{array}$ & 4,389 & 0,246 & 4 & 5 & 7,678 & 0,551 & 6,9 & 8,45 & 6,699 & 0,959 & $5,4 \quad 8,05$ & 21,269 & 2,630 & 17,75 & 25,7 & 7,874 & 0,796 & $6,959,5$ & 9,55 \\
\hline $\mathrm{HHI}-\mathrm{H}$ & Herfindahl index bank & 0,088 & 0,077 & $0,0206 \quad 0,37$ & 0,040 & 0,002 & 0,040 & 0,04 & 0,130 & 0,019 & 0,11 & 0,16 & 0,028 & 0,004 & $0,02 \quad 0,03$ & 0,057 & 0,006 & 0,051 & 0,07 & 0,338 & 0,031 & $0,301 \quad 0,3$ & 0,37 \\
\hline Strength & Strength of the I & 5,859 & 1,778 & $\begin{array}{ll}3 & 9\end{array}$ & 7,00 & - & 7 & 7 & 6,00 & - & 6 & 6 & 7,00 & - & $\begin{array}{ll}7 & 7 \\
\end{array}$ & 6,00 & - & 6 & & 8,00 & & 8 & \\
\hline Pro_Protect & Property rights protection & 32,335 & 5,940 & $21 \quad 41$ & 90,00 & - & 90 & 90 & 80,00 & - & 80 & 80 & 90,00 & - & $90 \quad 90$ & 70,00 & - & 70 & 70 & 91,07 & 2,048 & 90 & 95 \\
\hline Time & Time to resolve a dispute & 599,638 & 293,93 & 2351210 & 397,00 & - & 3973 & 397 & 505,00 & & 505 & 505 & 394,00 & & $394 \quad 394$ & 515,00 & - & 515 & 515 & 364,68 & 36,595 & $235 \quad 37$ & 375 \\
\hline Cost_perc & Costs for settling a dispute & 19,070 & 5,663 & $\begin{array}{ll}13,3 & 29,9\end{array}$ & 18,00 & - & 18 & 18 & 17,70 & - & 17,7 & 17,7 & 14,40 & - & $14,4 \quad 14,4$ & 17,20 & - & 17,2 & 17,2 & 13,30 & - & $13,3 \quad 13$ & 13,3 \\
\hline N_procedures & Number of procedural steps & 32,335 & 5,940 & $21 \quad 41$ & 25,00 & & 25 & 25 & 26,00 & & 26 & 26 & 30,00 & & $30 \quad 30$ & 40,51 & 0,500 & 40 & 41 & 33,00 & & 33 & 33 \\
\hline
\end{tabular}


Table 1A Basic Statistics - Overall Dataset Continued

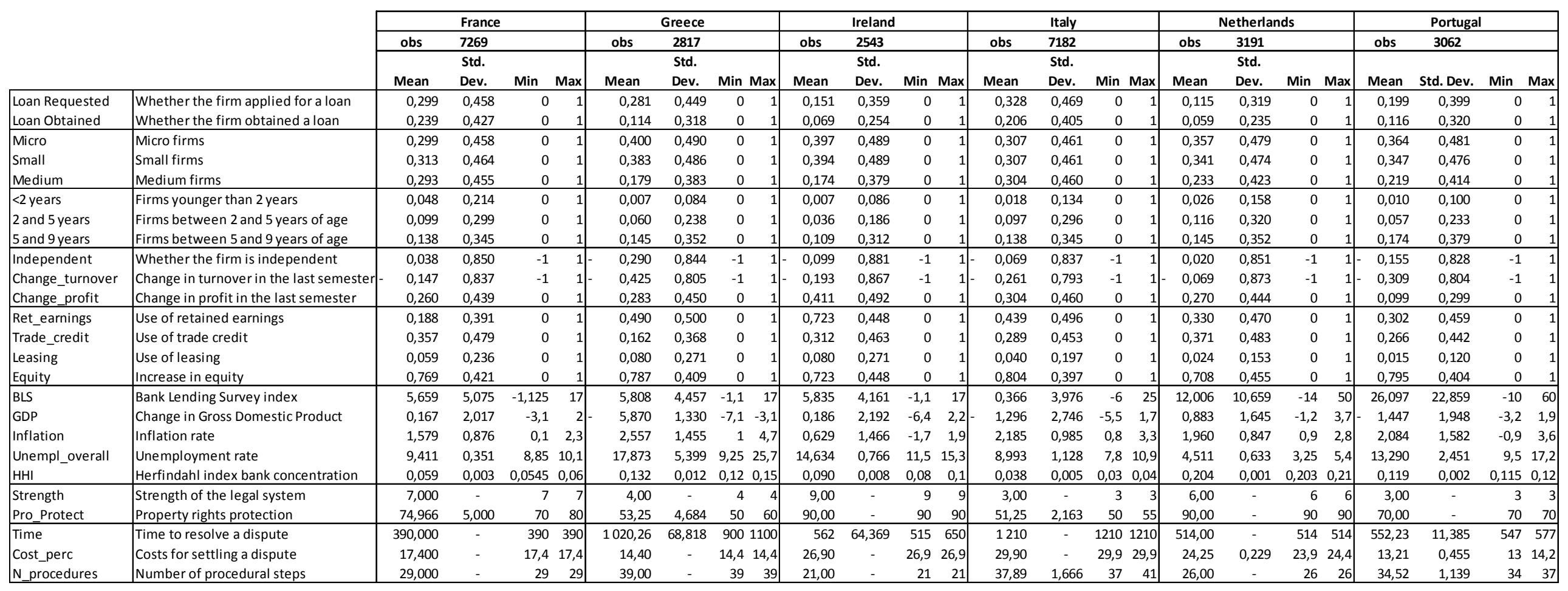




\section{Table 1B Basic Statistics - Loan Obtained}

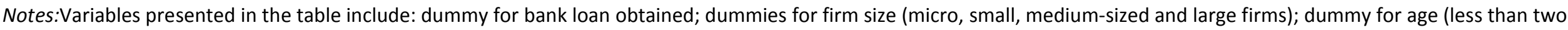

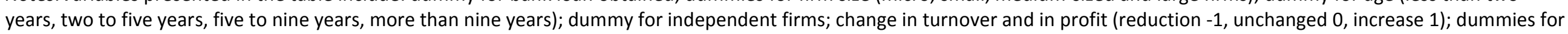

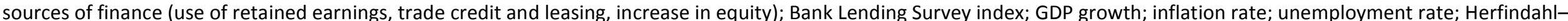

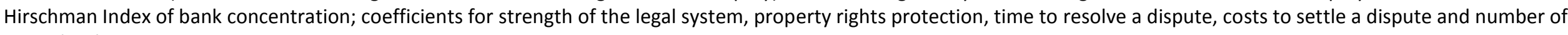
procedural steps.

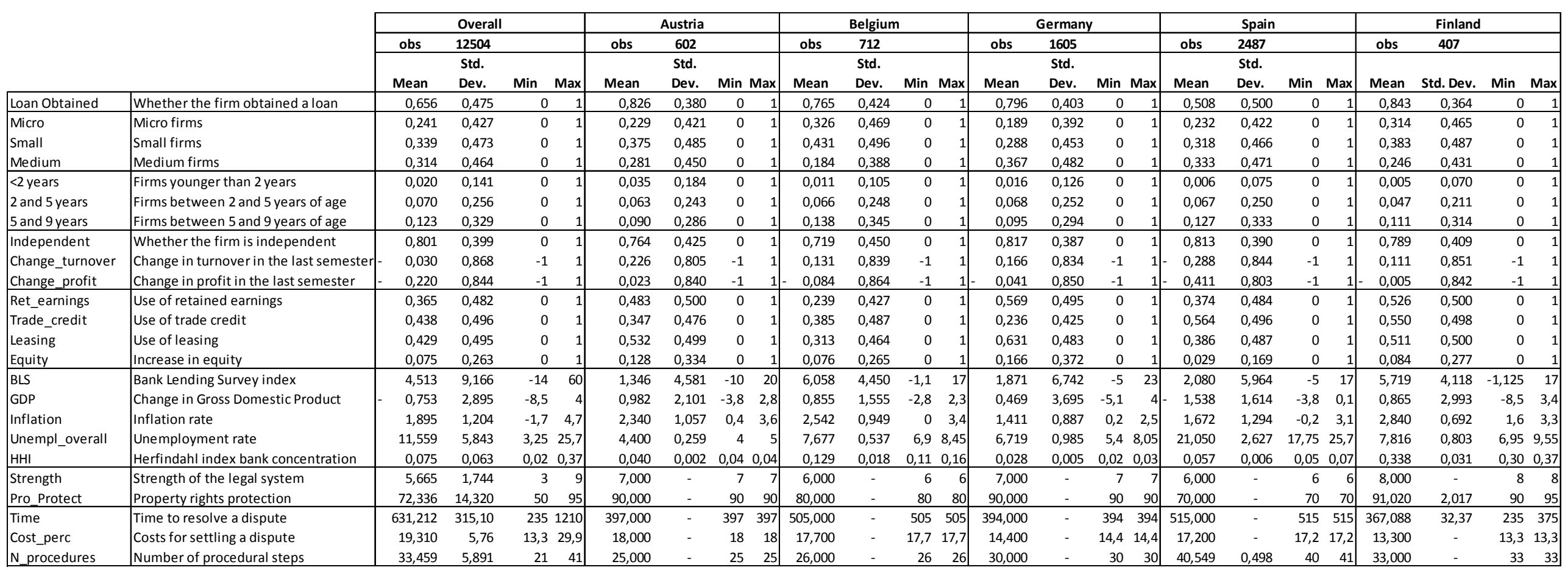




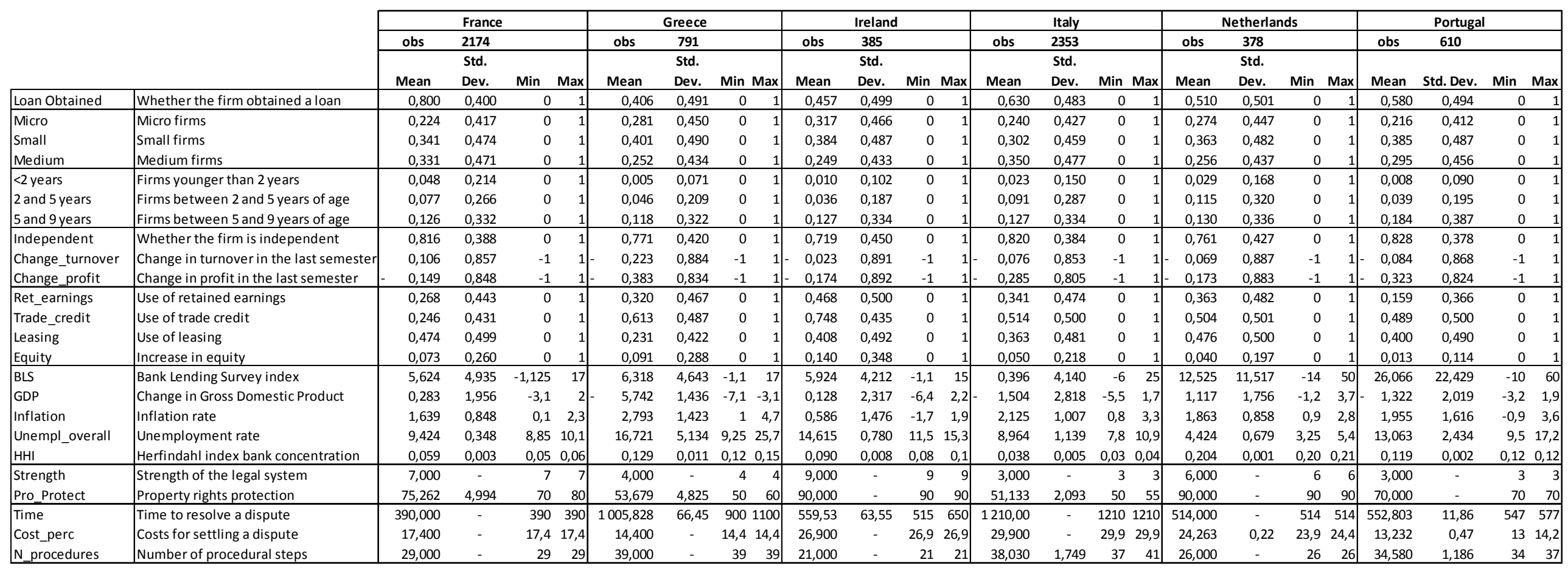


Table 2 Regressions - Obtaining Credit

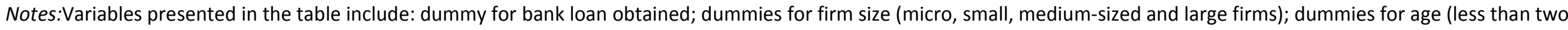
years, two to five years, five to nine years, more than nine years); dummies for sources of finance (use of retained earnings, trade credit and leasing, increase in equity); Bank

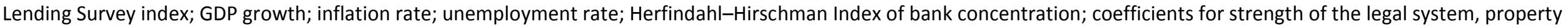
rights protection, time to resolve a dispute, costs to settle a dispute and number of procedural steps.

Sig.: ${ }^{*}<.1 ; * *<.05 ; * * *<.01$

\begin{tabular}{|c|c|c|c|c|c|c|c|c|c|c|c|c|c|c|c|c|c|c|c|}
\hline & & & cification & & & cification & & & ecification & & Spec & cification & & Spec & cification & & & ecification & \\
\hline & & Number & of obs & 12504 & Number & of obs & 12504 & Number & of obs & 12504 & Number of & f obs & 12504 & Number of & f obs & 12504 & Numbero & of obs & 12504 \\
\hline & & LR chi2 2 & & 1021,15 & LR chi2 2 & & 1109,54 & LR $\operatorname{chi} 2(2$ & & 1068,63 & LR chi2(22) & & 1028,06 & LR chi2(22) & & 1173,44 & $L R$ chi2 222 & & 1178,42 \\
\hline & & Prob $>$ ch & & & Prob >ch & & 0,0000 & Prob $>$ ch & & 0,0000 & Prob >chi2 & & 0,0000 & Prob > chi2 & & 0,0000 & Prob >chi & & 0,0000 \\
\hline Bank loan obtain & & Pseudo R & & 0,0634 & Pseudo R & & 0,0689 & Pseudo $\mathrm{F}$ & & 0,0664 & Pseudo R2 & & 0,0639 & Pseudo R2 & & 0,0729 & Pseudo R & & 0,0732 \\
\hline Variable Code & Description & \begin{tabular}{|l|} 
Coef. \\
\end{tabular} & Std. Err. & $P>Z$ & Coef. & Std. Err. & $P>z$ & Coef. & Std. Err. & $P>Z$ & Coef. & Std. Err. & $P>z$ & Coef. & Std. Err. & $P>z$ & Coef. & Std. Err. & $P>z$ \\
\hline \begin{tabular}{|l|} 
Micro \\
\end{tabular} & Micro firms & $-0,6064$ & 0,0775 & $* * *$ & $-0,6140$ & 0,0778 & $* * *$ & $-0,6153$ & 0,0777 & $* * *$ & $-0,6162$ & 0,0776 & *** & $-0,6284$ & 0,0781 & *** & $-0,6232$ & 0,0782 & $* * *$ \\
\hline Small & Small firms & $-0,2728$ & 0,0729 & $* * *$ & $-0,2746$ & 0,0732 & $* * *$ & $-0,2804$ & 0,0731 & $* * *$ & $-0,2832$ & 0,0731 & $* * *$ & $-0,2972$ & 0,0735 & $* * *$ & $-0,2977$ & 0,0736 & $* * *$ \\
\hline Medium & Medium firms & $-0,1092$ & 0,0730 & & $-0,1000$ & 0,0732 & & $-0,1089$ & 0,0731 & & $-0,1133$ & 0,0730 & & $-0,1228$ & 0,0735 & $*$ & $-0,1252$ & 0,0736 & $*$ \\
\hline$<2$ years & Firms younger than 2 years & $-0,1373$ & 0,1385 & & $-0,1763$ & 0,1392 & & $-0,1215$ & 0,1391 & & $-0,1493$ & 0,1387 & & $-0,1917$ & 0,1396 & & $-0,1401$ & 0,1394 & \\
\hline 2 and 5 years & Firms between 2 and 5 years of age & $-0,4470$ & 0,0756 & $* * *$ & $-0,4365$ & 0,0758 & $* * *$ & $-0,4341$ & 0,0758 & *** & $-0,4374$ & 0,0757 & *** & $-0,4378$ & 0,0760 & *** & $-0,4270$ & 0,0761 & $* * *$ \\
\hline 5 and 9 years & Firms between 5 and 9 years of age & $-0,2548$ & 0,0595 & $* * *$ & $-0,2262$ & 0,0599 & $* * *$ & $-0,2366$ & 0,0597 & $* * *$ & $-0,2481$ & 0,0596 & $* * *$ & $-0,2352$ & 0,0600 & $* * *$ & $-0,2420$ & 0,0599 & $* * *$ \\
\hline Ret_earnings & Use of retained earnings & $-0,0889$ & 0,0425 & ${ }^{* * *}$ & $-0,1220$ & 0,0428 & **** & $-0,1122$ & 0,0427 & **** & $-0,0887$ & 0,0425 & ** & $-0,1188$ & 0,0428 & ** & $-0,1152$ & 0,0428 & *** \\
\hline Trade_credit & Use of trade credit & $-0,2721$ & 0,0412 & $* * *$ & $-0,2282$ & 0,0416 & $* * *$ & $-0,2428$ & 0,0415 & $* * *$ & $-0,2690$ & 0,0412 & $* * *$ & $-0,1861$ & 0,0420 & *** & $-0,1753$ & 0,0421 & $* * *$ \\
\hline Leasing & Use of leasing & $-0,0245$ & 0,0417 & & $-0,0609$ & 0,0421 & & $-0,0546$ & 0,0421 & & $-0,0267$ & 0,0418 & & $-0,0775$ & 0,0422 & * & $-0,0722$ & 0,0422 & $*$ \\
\hline Equity & Increase in equity & $-0,2923$ & 0,0763 & $* * *$ & $-0,3449$ & 0,0767 & $* * *$ & $-0,3362$ & 0,0768 & $* * *$ & $-0,3071$ & 0,0764 & $* * *$ & $-0,3356$ & 0,0770 & $* * *$ & $-0,3662$ & 0,0775 & $* * *$ \\
\hline Semester & Semester (wave of collection) & & & & & & & & Incl & luded in & the regress & sions & & & & & & & \\
\hline BLS & Bank Lending Survey index & $-0,0098$ & 0,0025 & *** & $-0,0054$ & 0,0025 & ** & $-0,0104$ & 0,0025 & ${ }^{* * * *}$ & $-0,0103$ & 0,0025 & *** & $-0,0158$ & 0,0025 & **** & $-0,0178$ & 0,0026 & *** \\
\hline GDP & Change in Gross Domestic Product & 0,0903 & 0,0098 & $* * *$ & 0,0439 & 0,0110 & $* * *$ & 0,0517 & 0,0113 & $* * *$ & 0,0797 & 0,0106 & $* * *$ & 0,0167 & 0,0115 & & 0,0753 & 0,0098 & $* * *$ \\
\hline Inflation & Inflation rate & $-0,0248$ & 0,0228 & & 0,0607 & 0,0247 & $* *$ & 0,0286 & 0,0242 & & $-0,0100$ & 0,0236 & & 0,0401 & 0,0235 & * & $-0,0304$ & 0,0228 & \\
\hline Unempl_overall & Unemployment rate & $-0,0684$ & 0,0037 & $* * *$ & $-0,0760$ & 0,0038 & $* * *$ & $-0,0681$ & 0,0037 & $* * *$ & $-0,0622$ & 0,0044 & $* * *$ & $-0,0850$ & 0,0040 & $* * *$ & $-0,0860$ & 0,0040 & $* * *$ \\
\hline $\mathrm{HHI}$ & Herfindahl Index bank concentration & $-0,0171$ & 0,3510 & & $-1,0617$ & 0,3696 & $* * *$ & $-0,8528$ & 0,3728 & $* *$ & $-0,1774$ & 0,3530 & & $-1,0449$ & 0,3615 & $* * *$ & $-1,2857$ & 0,3652 & $* * *$ \\
\hline Strength & Strength of the legal system & & & & 0,1325 & 0,0141 & **** & & & & & & & & & & & & \\
\hline Pro_Protect & Property rights protection & & & & & & & 0,0129 & 0,0019 & $* * *$ & & & & & & & & & \\
\hline N_procedures & Number of procedural steps & & & & & & & & & & $-0,0129$ & 0,0049 & *** & & & & & & \\
\hline Time & Time to resolve a dispute & & & & & & & & & & & & & $-0,0973$ & 0,0001 & *** & & & \\
\hline Cost_perc & Costs for settling a dispute & & & & & & & & & & & & & & & & $-0,0488$ & 0,0039 & $* * *$ \\
\hline \begin{tabular}{|l|} 
cons \\
\end{tabular} & Constant & 2,3403 & 0,1051 & $* * *$ & 1,5038 & 0,1367 & $* * *$ & 1,3218 & 0,1804 & $* * *$ & 2,6791 & 0,1668 & $* * *$ & 3,0251 & 0,1212 & $* * *$ & 3,6388 & 0,1512 & $* * *$ \\
\hline
\end{tabular}


Table 3 Regressions - Obtaining Credit (Interaction with Property Protection)

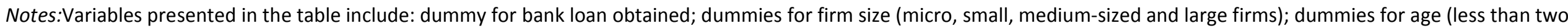

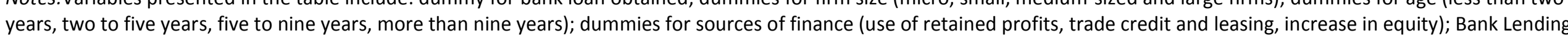
Survey index; GDP growth; inflation rate; unemployment rate; Herfindahl-Hirschman Index of bank concentration; coefficients for property rights protection, time to resolve a dispute, costs to settle a dispute and number of procedural steps.

Sig.: $*<.1 ; * *<.05 ; * * *<.01$

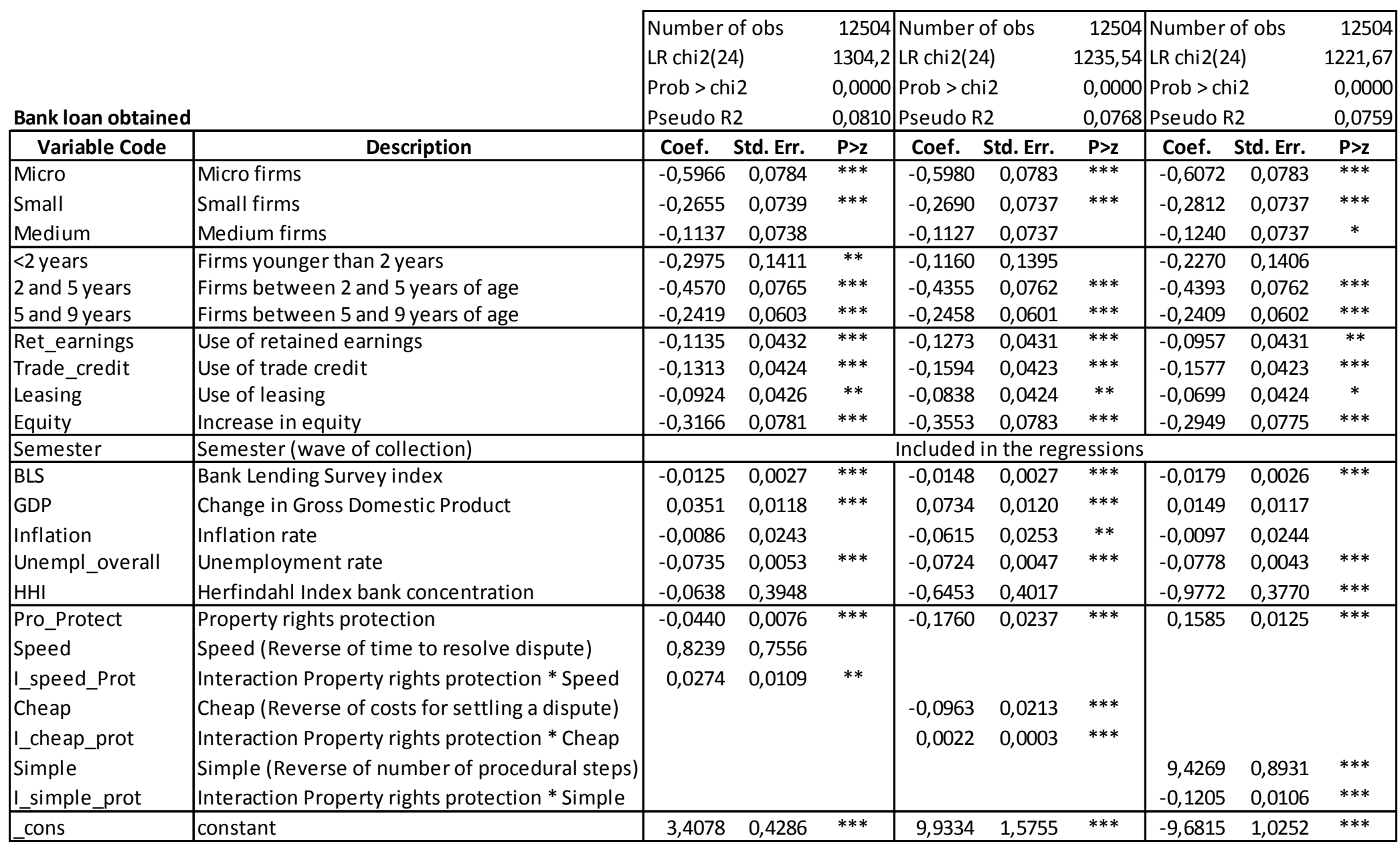


Table 4 Regressions - Obtaining Credit (Interaction with Strength of the Legal System)

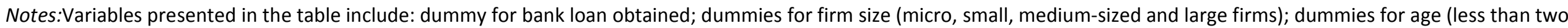
years, two to five years, five to nine years, more than nine years); dummies for sources of finance (use of retained earnings, trade credit and leasing, increase in equity); Bank Lending Survey index; GDP growth; inflation rate; unemployment rate; Herfindahl-Hirschman Index of bank concentration; coefficients for strength of the legal system, time to resolve a dispute, costs to settle a dispute and number of procedural steps.

Sig.: ${ }^{*}<.1 ; * *<.05 ; * * *<.01$

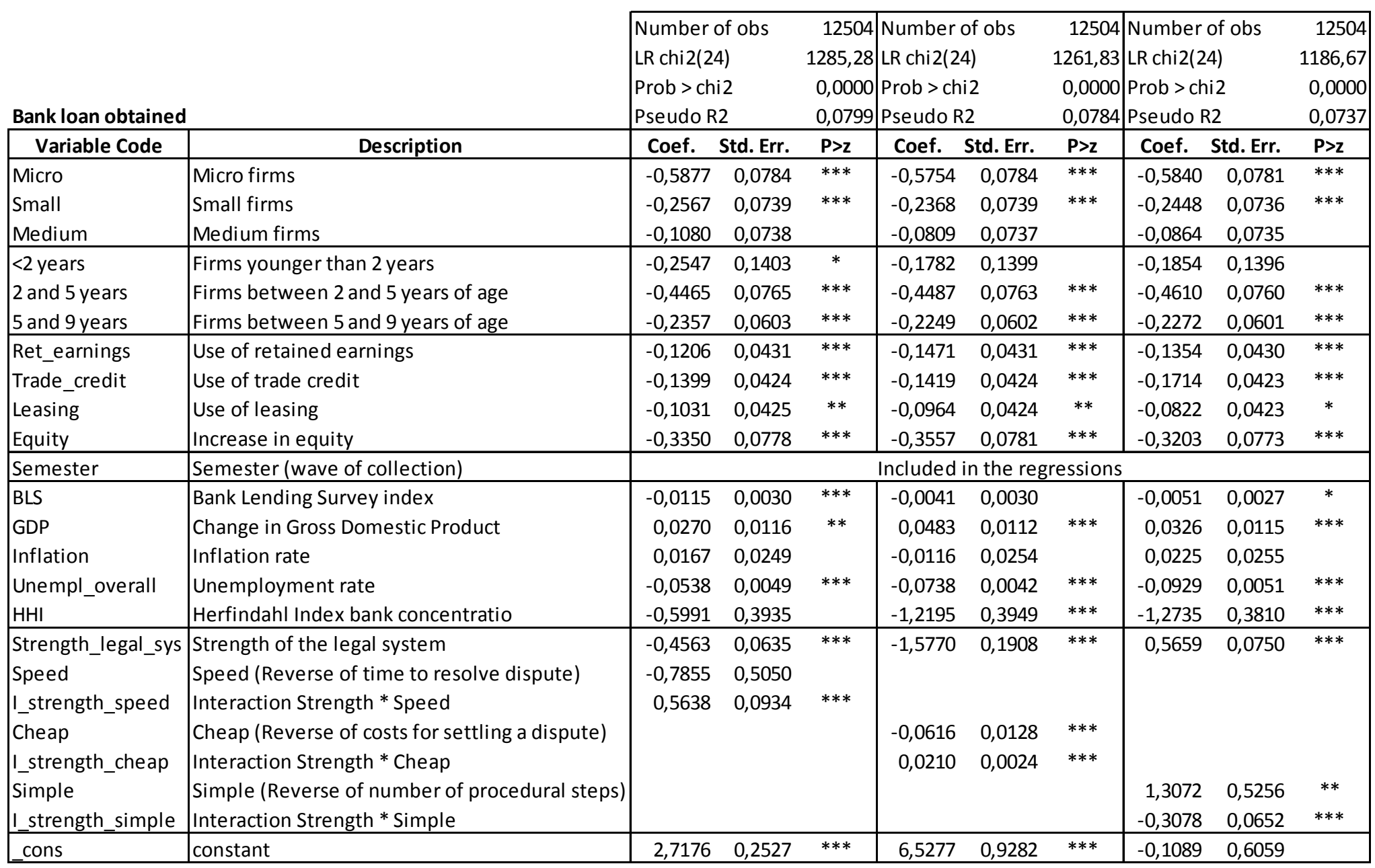


Table 5 Regressions - Obtaining Credit (Heckman Selection Model)

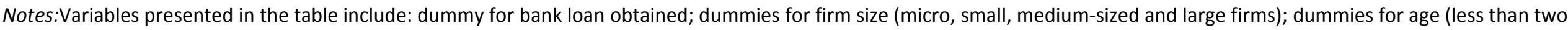
years, two to five years, five to nine years, more than nine years); dummies for sources of finance (use of retained earnings, trade credit and leasing, increase in equity); Bank

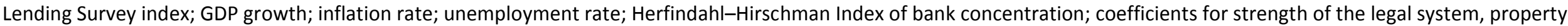

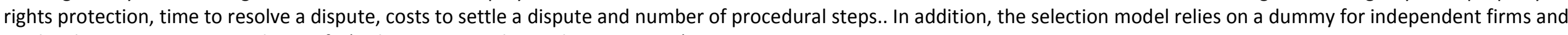
on the change in turnover and in profit (reduction -1 , unchanged 0 , increase 1 ).

Sig.: $*<.1 ; * *<.05 ; * * *<.01$

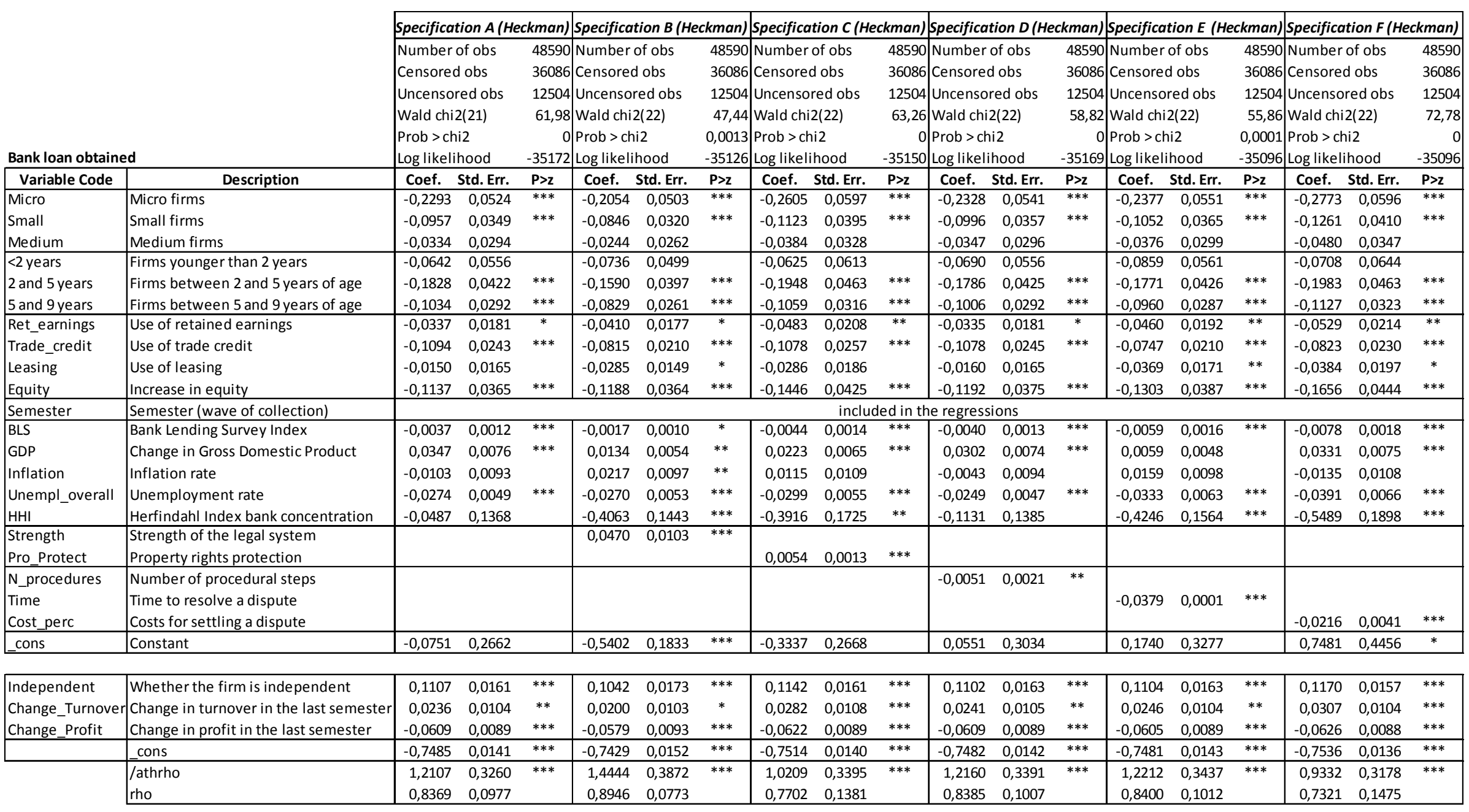


Table 6 Regression with Factor Weakness of the Judicial System

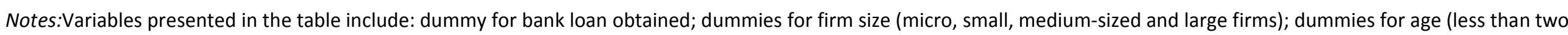
years, two to five years, five to nine years, more than nine years); dummies for sources of finance (use of retained earnings, trade credit and leasing, increase in equity); Bank Lending Survey index; GDP growth; inflation rate; unemployment rate; Herfindahl-Hirschman Index of bank concentration; factor for the weakness of the legal system. Sig.: * <.1; ${ }^{* *}<.05 ; * * *<.01$

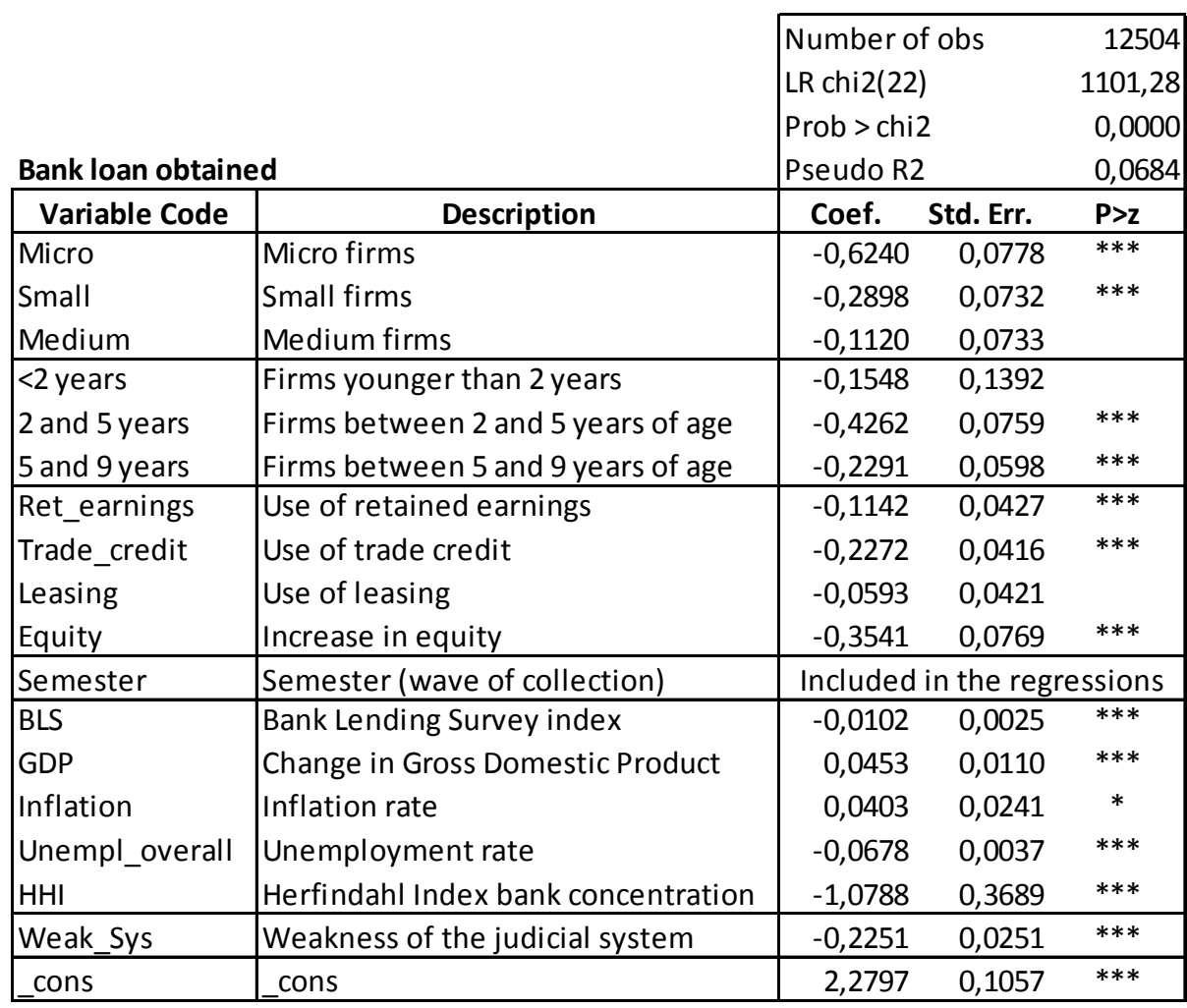


Table 7 Regression with Factor Weakness of the Judicial System (Factor with Heckman Selection)

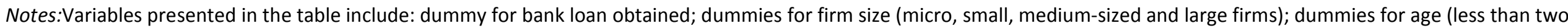
years, two to five years, five to nine years, more than nine years); dummies for sources of finance (use of retained earnings, trade credit and leasing, increase in equity); Bank

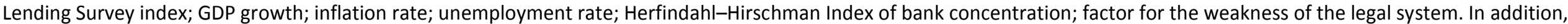
the selection model relies on a dummy for independent firms and on the change in turnover and in profit (reduction -1, unchanged 0 , increase 1 ).

Sig.: ${ }^{*}<.1 ;{ }^{* *}<.05 ;{ }^{* * *}<.01$

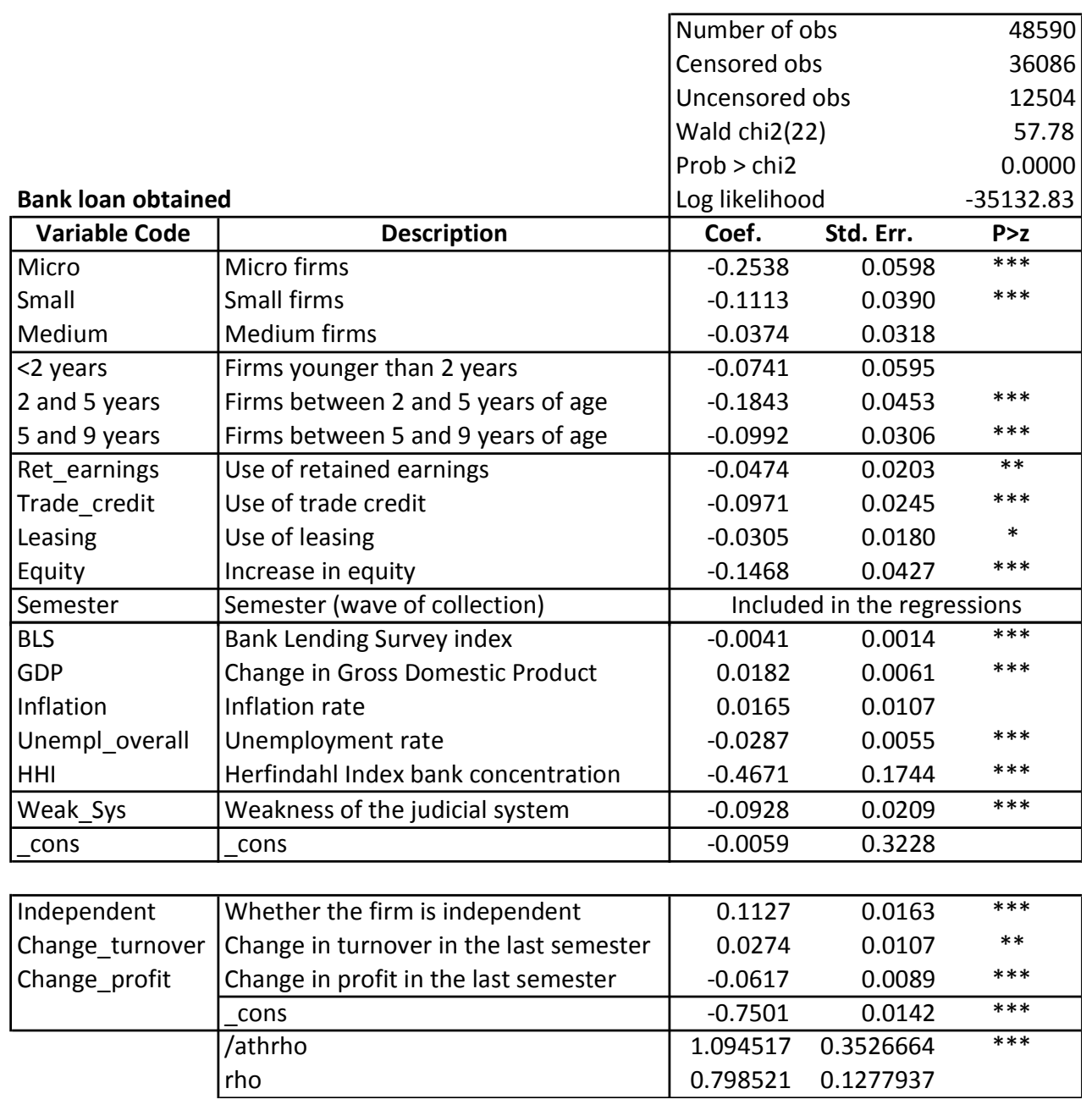


Table 8 Regressions - Subsample with Financial Performance

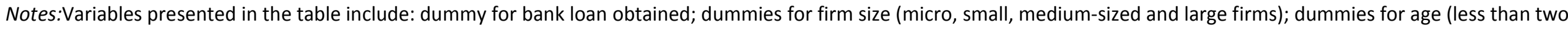
years, two to five years, five to nine years, more than nine years); financial performance of the firm: financial leverage (ratio of short-term and long-term debt to total assets), financial pressure (ratio of interest payments to EBITDA), profit margin (ratio of operating profits/losses to turnover) and collateral (ratio of fixed assets to total assets); Bank

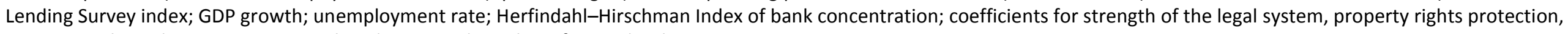
time to resolve a dispute, costs to settle a dispute and number of procedural steps.

Sig.: $*<.1 ; * * .05 ; * * *<.01$

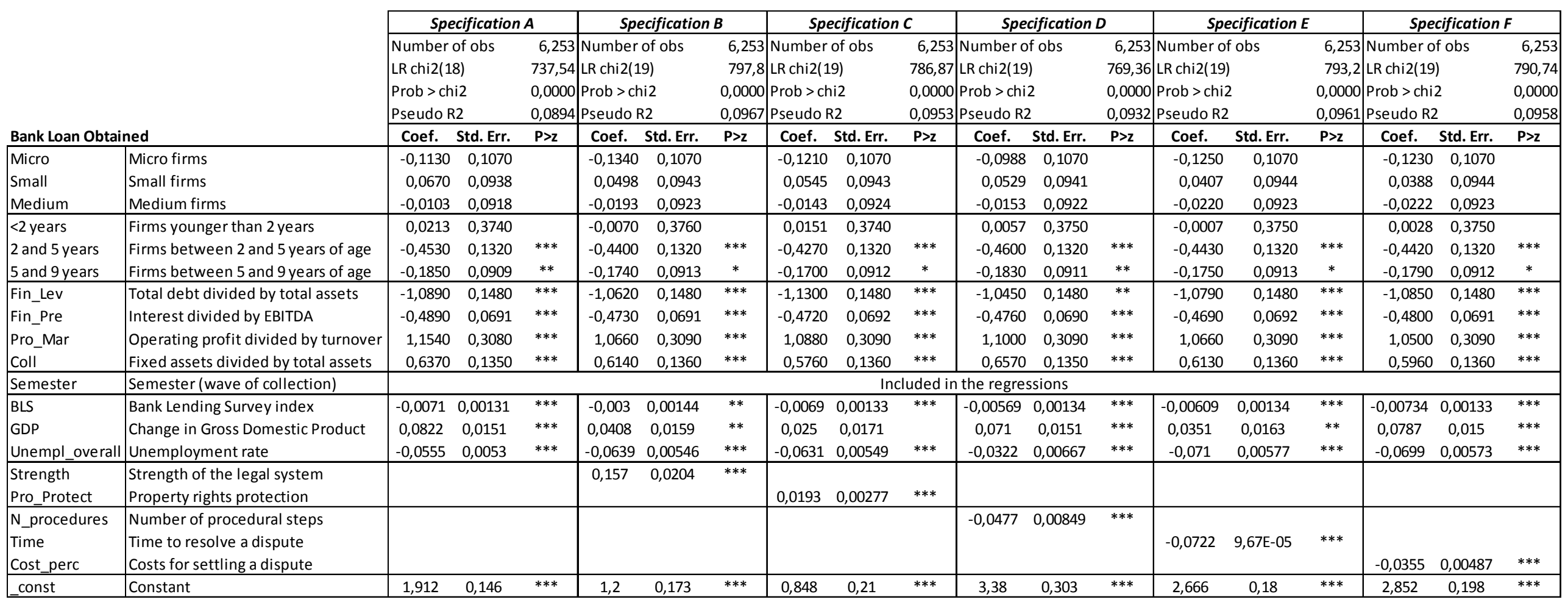


Table 9 Regressions - Subsample with Financial Performance (Heckman)

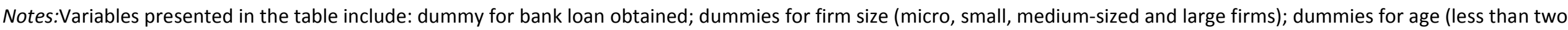
years, two to five years, five to nine years, more than nine years); financial performance of the firm: financial leverage (ratio of short-term and long-term debt to total assets), financial pressure (ratio of interest payments to EBITDA), profit margin (ratio of operating profits/losses to turnover) and collateral (ratio of fixed assets to total assets); Bank

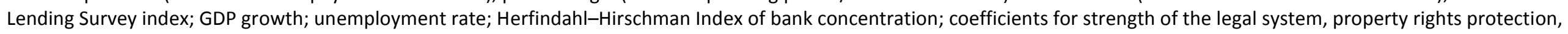

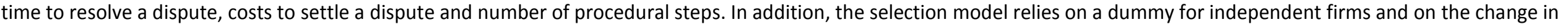
turnover and in profit (reduction -1 , unchanged 0 , increase, 1 ).

Sig.: ${ }^{*}<.1 ; * *<.05 ; * * *<.01$

\begin{tabular}{|c|c|c|c|c|c|c|c|c|c|c|c|c|c|c|c|c|c|c|c|}
\hline & \multicolumn{3}{|c|}{ Specification A (Heckman) } & \multicolumn{3}{|c|}{ ) Specification B (Heckman) } & \multicolumn{3}{|c|}{ Specification C (Heckman) } & \multicolumn{3}{|c|}{ Specification D (Heckman) } & \multicolumn{6}{|c|}{ Specification E (Heckman) Specification F (Heckman) } \\
\hline & & \multirow{4}{*}{\multicolumn{2}{|c|}{$\begin{array}{l}\text { Number of obs } \\
\text { Censored obs } \\
\text { Uncensored obs } \\
\text { Wald chi2(19) }\end{array}$}} & 38328 & \multicolumn{2}{|c|}{ Number of obs } & 38328 & \multicolumn{2}{|c|}{ Number of obs } & 38328 & \multicolumn{2}{|c|}{ Number of obs } & 38328 & \multicolumn{2}{|c|}{ Number of obs } & 38328 & \multicolumn{2}{|c|}{ Number of obs } & \multirow{6}{*}{$\begin{array}{r}38328 \\
31985 \\
6253 \\
337 \\
0 \\
-20628 \\
\end{array}$} \\
\hline & & & & 31985 & Censore & d obs & 31985 & Censorec & d obs & 31985 & Censorec & d obs & 31985 & Censore & d obs & 31985 & Censore & dobs & \\
\hline & & & & 6253 & Uncenso & red obs & 6253 & Uncenso & red obs & 6253 & Uncenso & red obs & 6253 & Uncenso & red obs & 6253 & Uncenso & red obs & \\
\hline & & & & 225,93 & Wald chi & i2(20) & 359,54 & Wald chi & i2(20) & 388,48 & Wald chi & $2(20)$ & 285,53 & Wald ch & 2(20) & 339,31 & Wald chi & i2(20) & \\
\hline & & \multirow{2}{*}{\multicolumn{2}{|c|}{ Log likelihood }} & & Prob $>$ ch & & & Prob $>$ ch & & & Prob $>$ ch & & & Prob $>c$ & & & Prob $>$ ch & & \\
\hline & & & & -20653 & \multicolumn{2}{|c|}{ Log likelihood } & \multirow{2}{*}{$P>2$} & \multicolumn{2}{|c|}{4 Log likelihood } & -20631 & \multirow{2}{*}{\multicolumn{2}{|c|}{$\frac{\text { Log likelihood }}{\text { Coef. Std. Err. }}$}} & -20638 & \multicolumn{2}{|c|}{ Log likelihood } & -20627 & \multicolumn{2}{|c|}{ Log likelihood } & \\
\hline & & Coef. & Std. Err. & $P>z$ & \begin{tabular}{|l|} 
Coef. \\
\end{tabular} & Std. Err. & & \begin{tabular}{|l|} 
Coef. \\
\end{tabular} & Std. Err. & $\mathrm{P}>\mathrm{Z}$ & & & $P>z$ & \begin{tabular}{|l|} 
Coef. \\
\end{tabular} & Std. Err. & $P>z$ & \begin{tabular}{|l|} 
Coef. \\
\end{tabular} & Std. Err. & $\mathbf{P}>\mathbf{Z}$ \\
\hline Micro & Micro firms & $-0,0538$ & 0,0622 & & $-0,0702$ & 0,0640 & & $-0,0638$ & 0,0642 & & $-0,0470$ & 0,0630 & & $-0,0646$ & 0,0638 & & $-0,0636$ & 0,0638 & \\
\hline Small & Small firms & 0,0519 & 0,0540 & & 0,0376 & 0,0558 & & 0,0412 & 0,0561 & & 0,0427 & 0,0550 & & 0,0335 & 0,0557 & & 0,0329 & 0,0557 & \\
\hline Medium & Medium firms & 0,0067 & 0,0529 & & $-0,0023$ & 0,0546 & & 0,0004 & 0,0548 & & 0,0025 & 0,0538 & & $-0,0032$ & 0,0545 & & $-0,0034$ & 0,0545 & \\
\hline$<2$ years & Firms younger than 2 years & $-0,0033$ & 0,2140 & & $-0,0212$ & 0,2200 & & 0,0048 & 0,2200 & & $-0,0141$ & 0,2170 & & $-0,0160$ & 0,2190 & & $-0,0120$ & 0,2190 & \\
\hline 2 and 5 years & Firms between 2 and 5 years of age & $-0,2650$ & 0,0780 & $* * *$ & $-0,2640$ & 0,0795 & $* * *$ & $-0,2530$ & 0,0797 & *** & $-0,2720$ & 0,0790 & *** & $-0,2650$ & 0,0794 & *** & $-0,2630$ & 0,0793 & *** \\
\hline 5 and 9 years & Firms between 5 and 9 years of age & $-0,1080$ & 0,0527 & ** & $-0,1050$ & 0,0541 & $*$ & $-0,1140$ & 0,0543 & $* * *$ & $-0,1090$ & 0,0535 & $* *$ & $-0,1060$ & 0,0540 & $*$ & $-0,1080$ & 0,0539 & $* *$ \\
\hline Fin_Lev & Total debt divided by total assets & $-0,6190$ & 0,0914 & *** & $-0,6200$ & 0,0904 & *** & $-0,6620$ & 0,0908 & ** & $-0,6060$ & 0,0905 & *** & $-0,6290$ & 0,0906 & *** & $-0,6330$ & 0,0906 & *** \\
\hline Fin_Pre & Interest divided by EBITDA & $-0,2810$ & 0,0420 & $* * *$ & $-0,2820$ & 0,0417 & $* * *$ & $-0,2820$ & 0,0417 & *** & $-0,2800$ & 0,0418 & $* * *$ & $-0,2780$ & 0,0418 & *** & $-0,2850$ & 0,0418 & $* * *$ \\
\hline Pro_Mar & Operating profit divided by turnover & 0,6520 & 0,1780 & $* * *$ & 0,6200 & 0,1810 & $* * *$ & 0,6340 & 0,1820 & *** & 0,6360 & 0,1790 & $* * *$ & 0,6210 & 0,1810 & *** & 0,6120 & 0,1810 & *** \\
\hline Coll & Fixed assets divided by total assets & 0,3700 & 0,0795 & $* * *$ & 0,3680 & 0,0807 & $* * *$ & 0,3460 & 0,0809 & $* * *$ & 0,3890 & 0,0801 & $* * *$ & 0,3670 & 0,0805 & *** & 0,3570 & 0,0804 & $* * *$ \\
\hline Semester & Semester (wave of collection) & & & & & & & & incle & Ided in & the regres & ssions & & & & & & & \\
\hline BLS & Bank Lending Survey index & $-0,0041$ & 0,0008 & $* *$ & $-0,0018$ & 0,0009 & $* *$ & $-0,0041$ & 0,0008 & $* * *$ & $-0,0033$ & 0,0008 & $* * *$ & $-0,0035$ & 0,0008 & *** & $-0,0043$ & 0,0008 & $* * *$ \\
\hline GDP & Change in Gross Domestic Product & 0,0464 & 0,0091 & $* * *$ & 0,0234 & 0,0095 & $* * *$ & 0,0153 & 0,0102 & * & 0,0410 & 0,0091 & $* * *$ & 0,0202 & 0,0097 & $* *$ & 0,0453 & 0,0091 & *** \\
\hline Unempl_overall & Unemployment rate & $-0,0324$ & 0,0036 & $* * *$ & $-0,0379$ & 0,0036 & $* * *$ & $-0,0374$ & 0,0035 & $* * *$ & $-0,0196$ & 0,0040 & *** & $-0,0419$ & 0,0038 & $* * *$ & $-0,0411$ & 0,0038 & $* * *$ \\
\hline $\begin{array}{l}\text { Strength } \\
\text { Pro_Protect }\end{array}$ & $\begin{array}{l}\text { Strength of the legal system } \\
\text { Property rights protection }\end{array}$ & & & & 0,0908 & 0,0126 & **** & 0,0108 & 0,0017 & $* * *$ & & & & & & & & & \\
\hline N_procedures & Number of procedural steps & & & & & & & & & & $-0,0267$ & 0,0057 & *** & & & & & & \\
\hline Time & Time to resolve a dispute & & & & & & & & & & & & & $-0,0417$ & 0,0060 & *** & & & \\
\hline Cost_perc & Costs for settling a dispute & & & & & & & & & & & & & & & & $-0,0203$ & 0,0032 & $* * *$ \\
\hline _const & Constant & 0,5840 & 0,3410 & $*$ & 0,3620 & 0,3190 & & 0,2150 & 0,3190 & & 1,4950 & 0,4010 & **** & 1,1870 & 0,3620 & $* * *$ & 1,2820 & 0,3660 & **** \\
\hline Independent & Whether the firm is independent & 0,0258 & 0,0258 & *** & 0,0255 & 0,0257 & *** & 0,0256 & 0,0257 & $* * *$ & 0,0257 & 0,0258 & *** & 0,0256 & 0,0257 & *** & 0,0256 & 0,0257 & $* * *$ \\
\hline Change_Turnover & Change in turnover in the last semester & 0,0116 & 0,0116 & $* * *$ & 0,0115 & 0,0115 & $* * *$ & 0,0115 & 0,0115 & $* * *$ & 0,0115 & 0,0116 & ** & 0,0115 & 0,0115 & ** & 0,0115 & 0,0115 & $* * *$ \\
\hline Change_Profit & Change in profit in the last semester & 0,0118 & 0,0119 & $* * *$ & 0,0119 & 0,0120 & *** & 0,0120 & 0,0120 & $* * *$ & 0,0119 & 0,0120 & $* * *$ & 0,0119 & 0,0120 & $* * *$ & 0,0119 & 0,0120 & $* * *$ \\
\hline & cons & $-1,2590$ & 0,0243 & $* * *$ & $-1,2610$ & 0,0241 & $* * *$ & $-1,2620$ & 0,0241 & $* * *$ & $-1,2600$ & 0,0242 & $* * *$ & $-1,2600$ & 0,0241 & $* * *$ & $-1,2610$ & 0,0241 & $* * *$ \\
\hline & /athrho & 0,355 & 0,199 & $*$ & 0,239 & 0,193 & & 0,2147 & 0,194 & & 0,297 & 0,194 & & 0,251 & 0,196 & & 0,255 & 0,193 & \\
\hline & rho & 0,341 & 0,176 & & 0,235 & 0,182 & & 0,212 & 0,186 & & 0,289 & 0,288 & & 0,246 & 0,183 & & 0,25 & 0,181 & \\
\hline
\end{tabular}


Table 10 - Regressions: More than $75 \%$ of the Bank Loan Obtained

Notes:Variables presented in the table include: dummy for partial bank loan obtained (more than 75\%); dummies for firm size (micro, small, medium-sized and large firms);

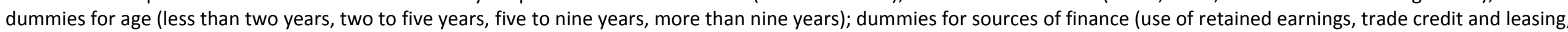

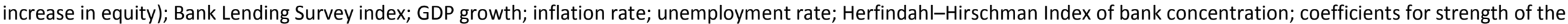
legal system, property rights protection, time to resolve a dispute, costs to settle a dispute and number of procedural steps.

Sig.: ${ }^{*}<.1 ; * *<.05 ; * * *<.01$

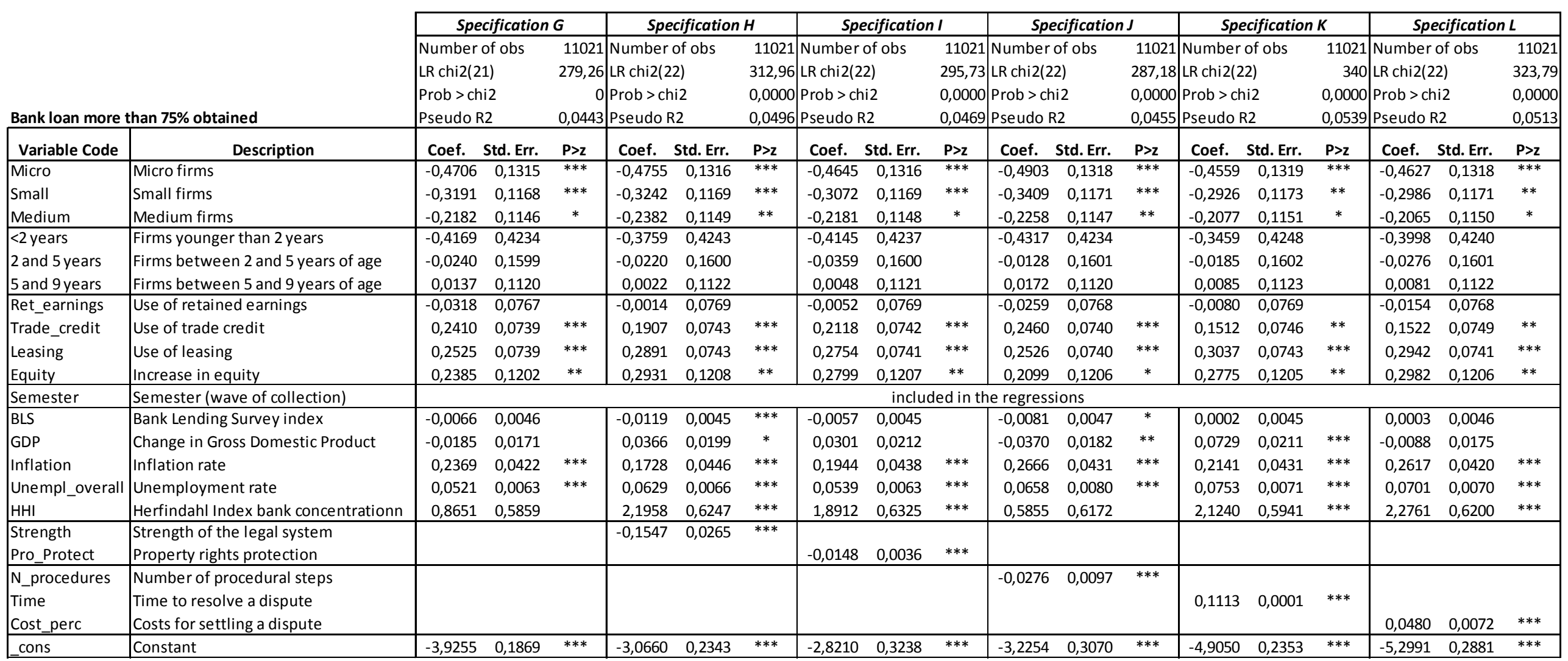


Table 11 - Regressions: Less than $75 \%$ of the Bank Loan Obtained

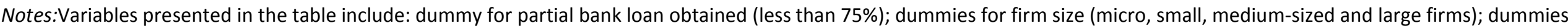

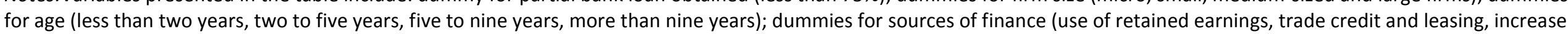
in equity); Bank Lending Survey index; GDP growth; inflation rate; unemployment rate; Herfindahl-Hirschman Index of bank concentration; coefficients for strength of the legal system, property rights protection, time to resolve a dispute, costs to settle a dispute and number of procedural steps.

Sig.: ${ }^{*}<.1 ; * *<.05 ; * * *<.01$

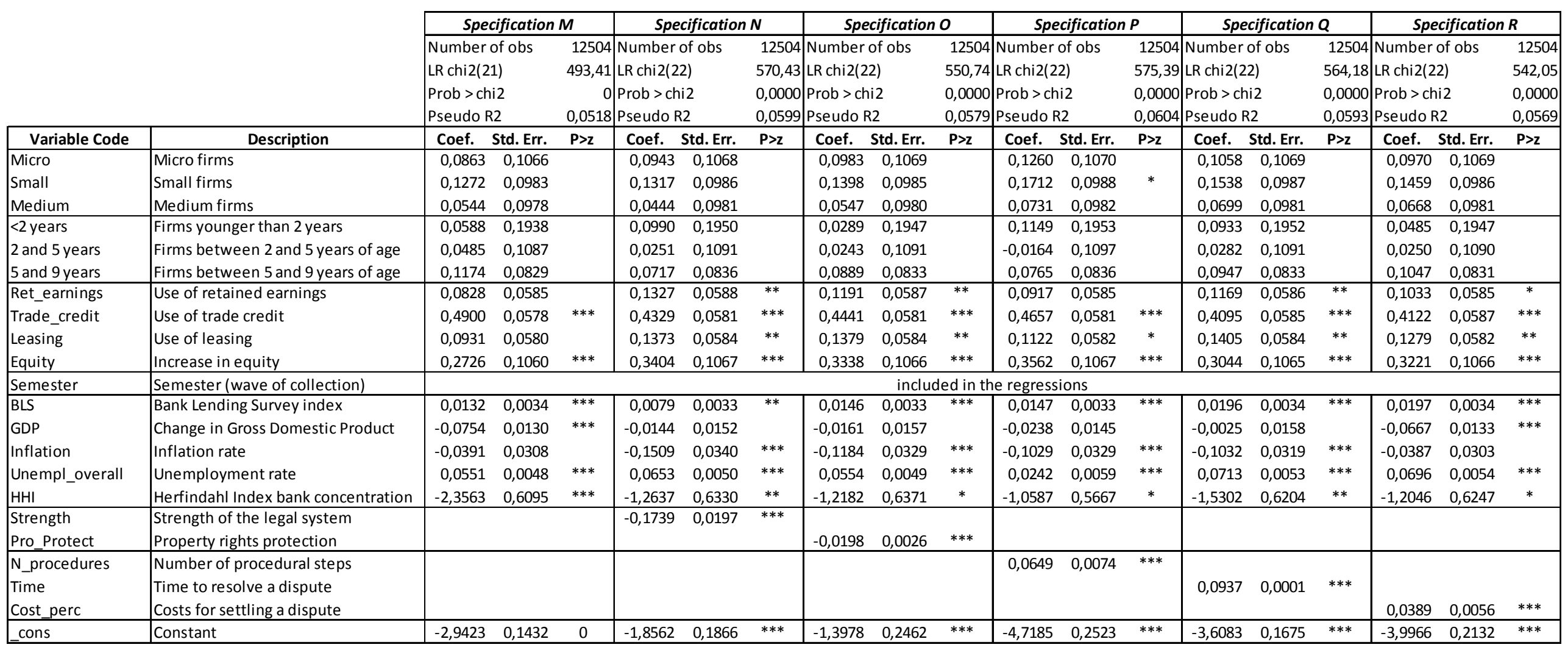


Table 12 - Change in the Coefficients for the Probability to be Granted the Entire or Part of the Loan

Notes: The table reports the change in the coefficients for the probability to be granted the entire loan (All), the bulk of the credit requested (>75\%) or only a proportion of it $(<75 \%)$.

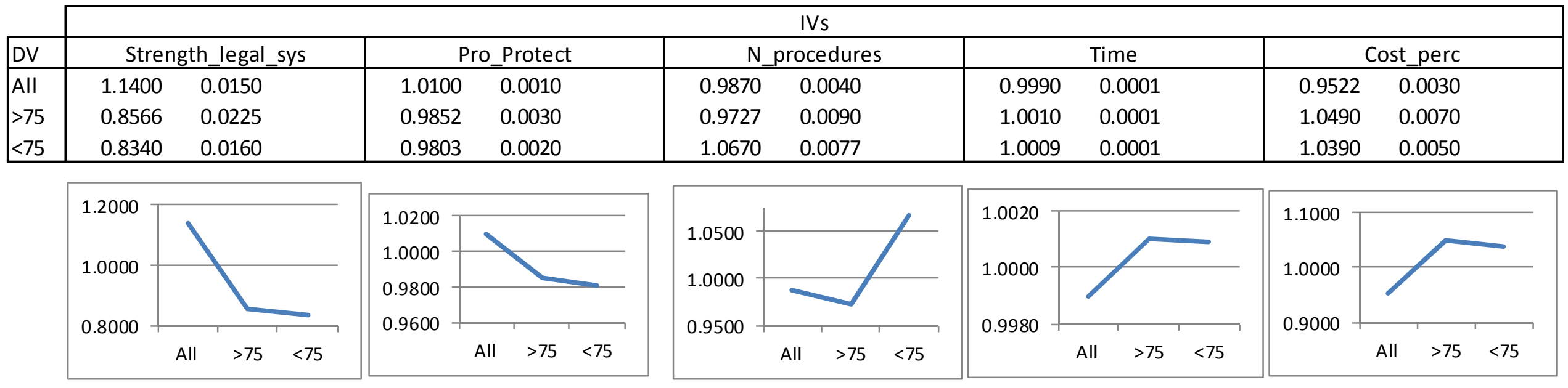


Table 13 - Economic Impact of Creditor Rights and Judicial Enforcement on the Probability to Obtain Credit

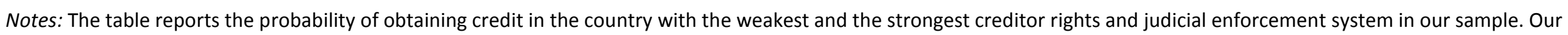
results are reported for each of the five independent variables used to evaluate the quality of creditor rights and the judicial enforcement system.

\begin{tabular}{|c|c|c|}
\hline & Min & Max \\
\hline \multirow[t]{2}{*}{ Strength of the legal system } & $(I T=3)$ & $(\mathrm{IE}=9)$ \\
\hline & 0,5870 & 0,7589 \\
\hline \multirow[t]{2}{*}{ Property rights protection } & $(I T=50)$ & $(\mathrm{FI} / \mathrm{NL} / \mathrm{DE}=90)$ \\
\hline & 0,6026 & 0,7172 \\
\hline \multirow[t]{2}{*}{ Number of procedural steps } & $(E S=41)$ & $(\mathrm{IE}=21)$ \\
\hline & 0,6459 & 0,7024 \\
\hline \multirow[t]{2}{*}{ Time to resolve a dispute } & $(\mathrm{IT}=1210)$ & $(\mathrm{Fl}=235)$ \\
\hline & 0,5368 & 0,7495 \\
\hline \multirow[t]{2}{*}{ Costs for settling a dispute } & $(I T=29.9)$ & $(\mathrm{FI}=13.3)$ \\
\hline & 0,5499 & 0,7330 \\
\hline
\end{tabular}

